\title{
Joint lavage for osteoarthritis of the knee (Review)
}

Reichenbach S, Rutjes AWS, Nüesch E, Trelle S, Jüni P

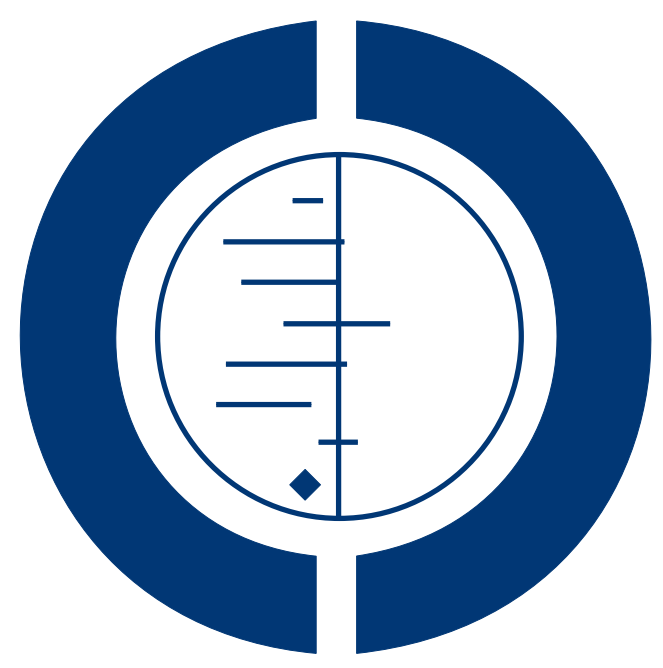

\section{THE COCHRANE COLLABORATION $^{\circledR}$}

This is a reprint of a Cochrane review, prepared and maintained by The Cochrane Collaboration and published in The Cochrane Library 2010, Issue 5

http://www.thecochranelibrary.com

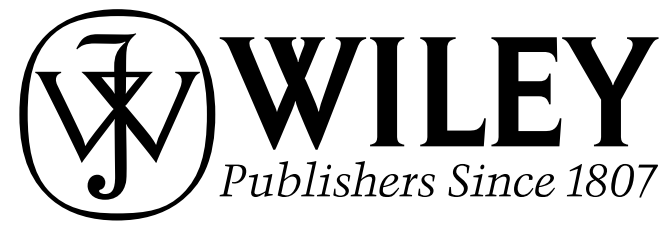

Joint lavage for osteoarthritis of the knee (Review)

Copyright (C) 2010 The Cochrane Collaboration. Published by John Wiley \& Sons, Ltd. 
TABLE OF CONTENTS

HEADER . . . . . . . . . . . . . . . . . . . . . . . . . . . . . . . . . . . . . . . 1

ABSTRACT . . . . . . . . . . . . . . . . . . . . . . . . . . . . . . . . . . . . . . . . . . . 1

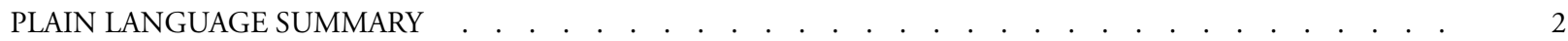

SUMMARY OF FINDINGS FOR THE MAIN COMPARISON . . . . . . . . . . . . . . . . . . . . . 2

BACKGROUND . . . . . . . . . . . . . . . . . . . . . . . . . . . . . . . . . . . . 6

OBJECTIVES . . . . . . . . . . . . . . . . . . . . . . . . . . . . . . . . . . . . . 6

METHODS . . . . . . . . . . . . . . . . . . . . . . . . . . . . . . . . . . . . . . 6

RESULTS . . . . . . . . . . . . . . . . . . . . . . . . . . . . . . . . . 8

Figure 1. . . . . . . . . . . . . . . . . . . . . . . . . . . . . . . . . . . . . . 9

Figure $2 . \quad$. . . . . . . . . . . . . . . . . . . . . . . . . . . . . . . . . . . . . 11

Figure 3. . . . . . . . . . . . . . . . . . . . . . . . . . . . . . . . . . . . . . 12

Figure 4. . . . . . . . . . . . . . . . . . . . . . . . . . . . . . . . . . . . . . 13

Figure 5. . . . . . . . . . . . . . . . . . . . . . . . . . . . . . . . . . . 14

Figure 6. . . . . . . . . . . . . . . . . . . . . . . . . . . . . . . . . . . . . . 16

Figure $7 . \quad$. . . . . . . . . . . . . . . . . . . . . . . . . . . . . . . . . . . 17

Figure 8. . . . . . . . . . . . . . . . . . . . . . . . . . . . . . . . . 18

Figure 9. . . . . . . . . . . . . . . . . . . . . . . . . . . . . . . . . . . . . . 21

DISCUSSION . . . . . . . . . . . . . . . . . . . . . . . . . . . . . . . . . . . . . . 21

AUTHORS' CONCLUSIONS . . . . . . . . . . . . . . . . . . . . . . . . . . . . . . . 22

ACKNOWLEDGEMENTS . . . . . . . . . . . . . . . . . . . . . . . . . . . . . . . . . . . 22

REFERENCES . . . . . . . . . . . . . . . . . . . . . . . . . . . . . . . . . . . . . 22

CHARACTERISTICS OF STUDIES . . . . . . . . . . . . . . . . . . . . . . . . . . . . . . . . . . . 24

DATA AND ANALYSES . . . . . . . . . . . . . . . . . . . . . . . . . . . . . . . . . . . . . . . . . . . . 35

Analysis 1.1. Comparison 1 Joint lavage for osteoarthritis of the knee, Outcome 1 Pain. . . . . . . . . . . . . 36

Analysis 1.2. Comparison 1 Joint lavage for osteoarthritis of the knee, Outcome 2 Function. . . . . . . . . . . . . 37

Analysis 2.1. Comparison 2 Any type of lavage versus sham intervention, Outcome 1 Pain. . . . . . . . . . . . 38

Analysis 2.2. Comparison 2 Any type of lavage versus sham intervention, Outcome 2 Function. . . . . . . . . . 39

Analysis 3.1. Comparison 3 Joint lavage for osteoarthritis of the knee: 1 year follow up, Outcome 1 Pain. . . . . $\quad 40$

Analysis 3.2. Comparison 3 Joint lavage for osteoarthritis of the knee: 1 year follow up, Outcome 2 Function. . . . $\quad 40$

APPENDICES . . . . . . . . . . . . . . . . . . . . . . . . . . . . . . . . . . . . . 40

WHAT'S NEW . . . . . . . . . . . . . . . . . . . . . . . . . . . . . . . . . . . . . 43

HISTORY . . . . . . . . . . . . . . . . . . . . . . . . . . . . . . . . . . . 43

CONTRIBUTIONS OF AUTHORS . . . . . . . . . . . . . . . . . . . . . . . . . . . . . . . . . . . . . . 43

DECLARATIONS OF INTEREST . . . . . . . . . . . . . . . . . . . . . . . . . . . . . . . . . . . . . $\quad .43$

SOURCES OF SUPPORT . . . . . . . . . . . . . . . . . . . . . . . . . . . . . . . . . . 44

DIFFERENCES BETWEEN PROTOCOL AND REVIEW . . . . . . . . . . . . . . . . . . . . . . 44

Joint lavage for osteoarthritis of the knee (Review)

Copyright $(2010$ The Cochrane Collaboration. Published by John Wiley \& Sons, Ltd. 


\title{
[Intervention Review]
}

\section{Joint lavage for osteoarthritis of the knee}

\author{
Stephan Reichenbach ${ }^{1}$, Anne WS Rutjes ${ }^{2}$, Eveline Nüesch ${ }^{2}$, Sven Trelle ${ }^{3}$, Peter Jüni ${ }^{2}$ \\ ${ }^{1}$ Department for Rheumatology, Clinical Immunology, and Allergology, University Hospital, Bern, Switzerland. ${ }^{2}$ Division of Clinical \\ Epidemiology and Biostatistics, Institute of Social and Preventive Medicine, University of Bern, Bern, Switzerland. ${ }^{3}$ Institute of Social \\ and Preventive Medicine, University of Bern, Bern, Switzerland \\ Contact address: Stephan Reichenbach, Department for Rheumatology, Clinical Immunology, and Allergology, University Hospital, \\ Inselspital, Bern, Switzerland. rbach@ispm.unibe.ch.
}

Editorial group: Cochrane Musculoskeletal Group.

Publication status and date: New, published in Issue 5, 2010.

Review content assessed as up-to-date: 2 August 2009.

Citation: Reichenbach S, Rutjes AWS, Nüesch E, Trelle S, Jüni P. Joint lavage for osteoarthritis of the knee. Cochrane Database of Systematic Reviews 2010, Issue 5. Art. No.: CD007320. DOI: 10.1002/14651858.CD007320.pub2.

Copyright (C) 2010 The Cochrane Collaboration. Published by John Wiley \& Sons, Ltd.

\section{A B S T R A C T}

\section{Background}

Osteoarthritis is the most common form of joint disorder and a leading cause of pain and physical disability. Observational studies suggested a benefit for joint lavage, but recent, sham-controlled trials yielded conflicting results, suggesting joint lavage not to be effective.

\section{Objectives}

To compare joint lavage with sham intervention, placebo or non-intervention control in terms of effects on pain, function and safety outcomes in patients with knee osteoarthritis.

\section{Search strategy}

We searched CENTRAL, MEDLINE, EMBASE, and CINAHL up to 3 August 2009, checked conference proceedings, reference lists, and contacted authors.

\section{Selection criteria}

We included studies if they were randomised or quasi-randomised trials that compared arthroscopic and non-arthroscopic joint lavage with a control intervention in patients with osteoarthritis of the knee. We did not apply any language restrictions.

\section{Data collection and analysis}

Two independent review authors extracted data using standardised forms. We contacted investigators to obtain missing outcome information. We calculated standardised mean differences (SMDs) for pain and function, and risk ratios for safety outcomes. We combined trials using inverse-variance random-effects meta-analysis.

\section{Main results}

We included seven trials with 567 patients. Three trials examined arthroscopic joint lavage, two non-arthroscopic joint lavage and two tidal irrigation. The methodological quality and the quality of reporting was poor and we identified a moderate to large degree of heterogeneity among the trials $\left(\mathrm{I}^{2}=65 \%\right)$. We found little evidence for a benefit of joint lavage in terms of pain relief at three months (SMD - $0.11,95 \%$ CI -0.42 to 0.21 ), corresponding to a difference in pain scores between joint lavage and control of $0.3 \mathrm{~cm}$ on a $10-\mathrm{cm}$ visual analogue scale (VAS). Results for improvement in function at three months were similar (SMD - $0.10,95 \%$ CI -0.30 to 
0.11), corresponding to a difference in function scores between joint lavage and control of $0.2 \mathrm{~cm}$ on a WOMAC disability sub-scale from 0 to 10. For pain, estimates of effect sizes varied to some degree depending on the type of lavage, but this variation was likely to be explained by differences in the credibility of control interventions: trials using sham interventions to closely mimic the process of joint lavage showed a null-effect. Reporting on adverse events and drop out rates was unsatisfactory, and we were unable to draw conclusions for these secondary outcomes.

\section{Authors' conclusions}

Joint lavage does not result in a relevant benefit for patients with knee osteoarthritis in terms of pain relief or improvement of function.

\section{PLAIN LANGUAGE SUMMARY}

\section{Joint lavage for osteoarthritis of the knee}

This summary of a Cochrane review presents what we know from research about the effect of joint lavage for osteoarthritis (OA) of the knee. The review shows that in people with OA, joint lavage;

- may not improve pain and function compared to a sham treatment or no treatment.

We often do not have precise information about side effects and complications. This is particularly true for rare but serious side effects.

\section{What is osteoarthritis and what is joint lavage}

Osteoarthritis (OA) is the most common form of arthritis that can affect the hands, hips, and knees. In OA, the cartilage breaks down and may cause swelling and consecutive pain. OA can occur in different areas of the knee or the whole knee. When the cartilage breaks down, bits of tissue are left around the knee joint, which can add to the inflammation and prevent the joint from working properly.

Joint lavage means to wash out any loose tissue or debris from inside the joint space. It involves temporally inserting small tubes into 1 or more entry points into the knee.

This systematic review discusses three types of joint lavage. Tidal irrigation joint lavage uses only one entry point to alternately inject fluid, and then draw it out. Non-arthroscopic joint lavage uses two entry points, one to inject the fluid and a separate one for the withdrawal of the fluid, but no visual inspection of the knee is performed. Arthroscopic joint lavage is a formal joint lavage in addition to a visually inspection of the knee joints structures as this is done. 


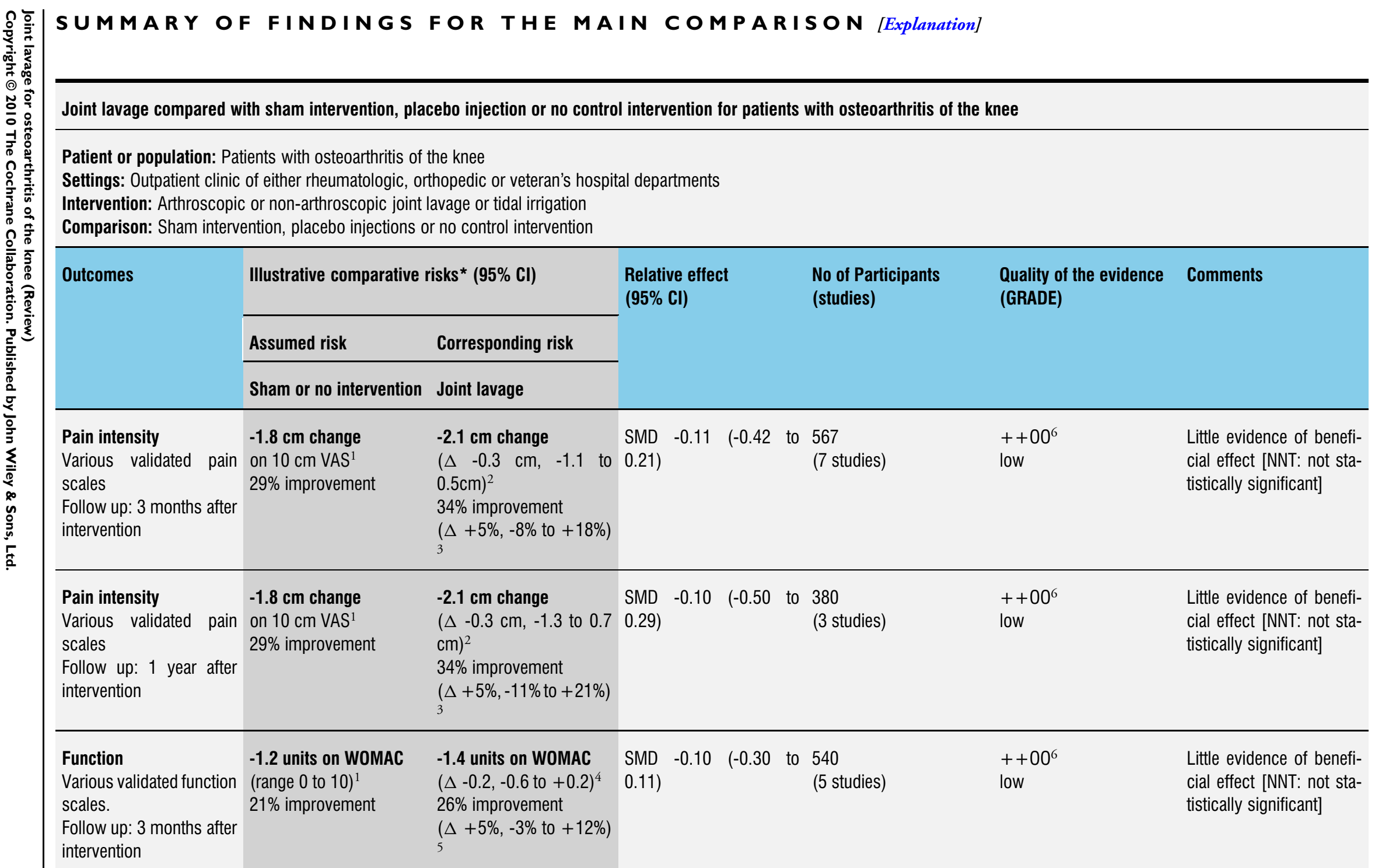




\begin{tabular}{|c|c|c|c|c|c|c|}
\hline $\begin{array}{l}\text { Function } \\
\text { Various validated function } \\
\text { scales. } \\
\text { Follow up: } 1 \text { year after } \\
\text { intervention }\end{array}$ & $\begin{array}{l}-1.2 \text { units on WOMAC } \\
{\text { (range } 0 \text { to } 10)^{1}}^{1} \\
21 \% \text { improvement }\end{array}$ & $\begin{array}{l}-1.6 \text { units on WOMAC } \\
(\Delta-0.4,-0.8 \text { to } 0.0)^{4} \\
28 \% \text { improvement } \\
(\Delta+7 \%, \quad+0 \% \quad \text { to } \\
+15 \%)^{5}\end{array}$ & $\begin{array}{llll}\text { SMD } & -0.17 \quad(-0.38 \text { to } \\
0.03) & & & \end{array}$ & $\begin{array}{l}381 \\
\text { (3 studies) }\end{array}$ & $\begin{array}{l}++00^{6} \\
\text { low }\end{array}$ & $\begin{array}{l}\text { Little evidence of benefi- } \\
\text { cial effect [NNT: not sta- } \\
\text { tistically significant] }\end{array}$ \\
\hline $\begin{array}{l}\begin{array}{l}\text { Number of patients } \\
\text { experiencing adverse } \\
\text { events }\end{array} \\
\text { Follow up: up to } 1 \text { year } \\
\text { after intervention }\end{array}$ & See comment & See comment & Not estimable & $\begin{array}{l}0 \\
\text { (0 study) }\end{array}$ & See comment & $\begin{array}{l}0 \text { trials provided data for } \\
\text { this outcome }\end{array}$ \\
\hline $\begin{array}{l}\text { Number of patients who } \\
\text { withdrew due to adverse } \\
\text { event } \\
\text { Follow up: up to } 1 \text { year } \\
\text { after intervention }\end{array}$ & $\begin{array}{l}150 \text { per } 1000 \text { patient- } \\
\text { years }^{1}\end{array}$ & Not estimable & Not estimable & $\begin{array}{l}8 \\
\text { (1 study) }\end{array}$ & $\begin{array}{l}+000^{7} \\
\text { very low }\end{array}$ & NNH not estimable \\
\hline $\begin{array}{l}\text { Number of patients ex- } \\
\text { periencing any serious } \\
\text { adverse event } \\
\text { Follow up: up to } 1 \text { year } \\
\text { after intervention }\end{array}$ & 4 per 1000 patient-years & Not estimable & Not estimable & $\begin{array}{l}98 \\
\text { (1 study) }\end{array}$ & $\begin{array}{l}+000^{7} \\
\text { very low }\end{array}$ & $\begin{array}{l}1 \text { serious adverse event } \\
\text { reported. NNH not es- } \\
\text { timable }\end{array}$ \\
\hline
\end{tabular}

*The basis for the assumed risk (e.g. the median control group risk across studies) is provided in footnotes. The corresponding risk (and its $95 \%$ confidence interval) is based on the assumed risk in the comparison group and the relative effect of the intervention (and its $95 \% \mathrm{Cl}$ ).

Cl: Confidence interval; SMD: Standardised mean difference; GRADE: GRADE Working Group grades of evidence (see explanations); OA: osteoarthritis; SD: standard deviation; SMD: standardised mean difference; NNT: number needed to treat; NNH: number needed to harm; VAS: visual analogue scale

GRADE Working Group grades of evidence

High quality $(++++)$ : Further research is very unlikely to change our confidence in the estimate of effect.

Moderate quality $(+++0)$ : Further research is likely to have an important impact on our confidence in the estimate of effect and may

change the estimate.

Low quality $(++\mathbf{0 0})$ : Further research is very likely to have an important impact on our confidence in the estimate of effect and is likely

to change the estimate.

Very low quality $(+000)$ : We are very uncertain about the estimate.

${ }^{1}$ Median reduction as observed across control groups in large OA trials (Nuesch 2009). 
MDs were back-transformed onto a $10 \mathrm{~cm}$ VAS on the basis of a typical pooled SD of $2.5 \mathrm{~cm}$ in trials that assessed pain using a VAS, and expressed as change based on an assumed standardised reduction of 0.72 standard deviation units in the control group.

3 The median observed pain score at baseline across control groups in large OA trials was $6.1 \mathrm{~cm}$ on a 10-cm VAS (Nuesch 2009).

${ }^{4}$ SMDs were back-transformed onto a 0 to 10 standardised WOMAC function score on the basis of a typical pooled SD of 2.1 in

trials that assessed function on WOMAC function scale and expressed as change based on an assumed standardised reduction of 0.58 standard deviation units in the control group.

5 The median observed standardised WOMAC function score at baseline across control groups in large OA trials was 5.6 units (Nuesch 2009).

Downgraded (2 levels) because number of randomised patients per trial and the number of patients overall were low, the confidence interval is wide, 4 out of 7 trials reported unclear of concealment of allocation methods, and only 2 trials reported analysis according to intention-to-treat principle.

Downgraded (3 levels) because inadequate reporting of secondary outcomes. 


\section{B A C K G R O U N D}

Osteoarthritis (OA) is the most common form of joint disease and the leading cause of pain and physical disability in the elderly (Altman 1996). It is characterised by focal areas of loss of articular cartilage in synovial joints, accompanied by subchondral bone changes, osteophyte formation at the joint margins, thickening of the joint capsule, and mild synovitis. Symptoms include pain, stiffness, and decreased range of motion, limiting daily activities and quality of life.

To manage symptoms of $\mathrm{OA}$, patients and healthcare providers often resort to multiple approaches, including lifestyle modifications, medications such as non-steroidal anti-inflammatory drugs, and physical therapy. When conservative therapy fails to relieve pain, surgery is often recommended. A variety of invasive interventions have been described, including non-arthroscopic and arthroscopic lavage, arthroscopic debridement, corrective osteotomy, and total knee replacement. Non-arthroscopic and arthroscopic lavage are widely used techniques, consisting of rinsing out the knee with up to 10 litres of fluid. Any intra-articular debris, such as micro- or macroscopic cartilage fragments or calcium phosphate crystals which may cause pain or inflammation, were suggested to be flushed out through cannulas (Bradley 2003)

Joint lavage can be technically grouped into three different categories, according to whether a visual inspection of the knee joint was performed and, in the absence of visual inspection, according to the number of entry sites. In this systematic review we will use the following terms to denominate these categories.

1. Tidal irrigation joint lavage: uses only one entry site for the sequential instillation and withdrawal of the irrigation fluid.

2. Non-arthroscopic joint lavage: two entry sites are used, one for the instillation of the irrigation fluid and one for the withdrawal, but no visual inspection of the knee is performed.

3. Arthroscopic joint lavage: in addition to an arthroscopy of the knee joint, a formal joint lavage is performed. In contrast to arthroscopic debridement, no instruments are used to mechanically debride or remove intraarticular tissue.

In a retrospective case series of arthroscopic lavage (Jackson 2003), more than $50 \%$ of patients reported significant relief of symptoms lasting between one and five years. The procedure was most effective when performed during the earlier stages of the degenerative process. An early study comparing lavage and physiotherapy with physiotherapy alone, showed clearly better pain relief in the lavage group, with effects again lasting for up to one year (Livesley 1991). However, results from one randomised controlled trial (RCT) suggested that arthroscopic lavage may not be effective compared to a sham intervention (Moseley 2002).

\section{O B J E C T I V E S}

We set out to compare joint lavage with a sham intervention, placebo injections, or a non-intervention control in terms of effects on pain, function, and safety in patients with knee OA.

\section{METHODS}

\section{Criteria for considering studies for this review}

\section{Types of studies}

RCTs or quasi RCTs with a control group receiving a sham intervention to closely mimic the process of joint lavage, placebo injections, or a non-intervention control. We considered trials using an unpredictable allocation sequence as randomised; we considered trials using potentially predictable allocation mechanisms, such as alternation or the allocation of patients according to date of birth, as quasi-randomised.

\section{Types of participants}

We included patients with osteoarthritis of the knee. We did not consider trials including exclusively patients with inflammatory arthritis, such as rheumatoid arthritis.

\section{Types of interventions}

Arthroscopic and non-arthroscopic, but not open lavage. We excluded arthroscopic debridement, which is covered in a separate Cochrane Review (Laupattarakasem 2008).

\section{Types of outcome measures}

Main outcomes were pain and function, as currently recommended for osteoarthritis trials (Altman 1996; Pham 2004). If data on more than one pain scale were provided for a trial, we referred to a previously described hierarchy of pain-related outcomes (Juni 2006; Reichenbach 2007) and extracted data on the pain scale that was highest on this list:

1. Global pain

2. Pain on walking

3. WOMAC osteoarthritis index pain sub score

4. Composite pain scores other than WOMAC

5. Pain on activities other than walking

6. Rest pain or pain during the night

7. WOMAC global algofunctional score

8. Lequesne osteoarthritis index global score

9. Other algofunctional scale

10. Patient's global assessment

11. Physician's global assessment

If data on more than one function scale were provided for a trial, we extracted data according to the hierarchy presented below. 
1. Global disability score

2. Walking disability

3. WOMAC disability sub score

4. Composite disability scores other than WOMAC

5. Disability other than walking

6. WOMAC global scale

7. Lequesne osteoarthritis index global score

8. Other algofunctional scale

9. Patient's global assessment

10. Physician's global assessment

If pain or function outcomes were reported at several time points, we extracted the measure at three months as the main outcome. As a secondary time point, we extracted pain and function data one year after the intervention, if available.

\section{Secondary outcomes}

Secondary outcomes were the number of patients experiencing any adverse event, patients who were withdrawn or dropped out because of adverse events, and patients experiencing any serious adverse events. Serious adverse events were defined as events resulting in in-patient hospitalisation, prolongation of hospitalisation, persistent or significant disability, congenital abnormality or birth defect of offspring, life-threatening events, or death.

\section{Search methods for identification of studies}

\section{Electronic searches}

We searched electronic databases of CENTRAL through The Cochrane Library (http://mrw.interscience.wiley.com/cochrane/ ), MEDLINE and EMBASE through the Ovid platform (www.ovid.com), CINAHL through EBSCOhost, all from implementation to August 03, 2009 using a combination of keywords and text words related to lavage combined with keywords and text words related to osteoarthritis and a validated filter for controlled clinical trials (Dickersin 1994). We have presented the search strategy in Appendix 1 and Appendix 2.

\section{Searching other resources}

We manually searched conference proceedings, used Science Citation Index to retrieve reports citing relevant articles, contacted content experts and trialists and screened reference lists of all obtained articles, including related reviews. Finally, we searched several clinical trial registries (www.clinicaltrials.gov, www.controlledtrials.com, www.actr.org.au, www.umin.ac.jp/ctr) to identify ongoing trials. The last update of the manual search was on August 31, 2009.

\section{Data collection and analysis}

\section{Selection of studies}

Two review authors independently evaluated all titles and abstracts for eligibility. We resolved disagreements by discussion. We did not apply any language restrictions. If multiple reports described the same trial, we considered all.

\section{Data extraction and management}

Two review authors (SR and AR) extracted trial information independently using a standardised, piloted data extraction form accompanied by a codebook. We resolved disagreements by consensus or discussion with a third author. We extracted the exact technique of the experimental intervention, the type of control, the amount of lavage fluid, patient characteristics (average age, gender, mean duration of symptoms), type of pain- or functionrelated outcome, trial design, trial size, duration of follow up, type and source of financial support and publication status. When necessary, we approximated means and measures of dispersion from figures in the reports. For cross-over trials, we extracted data from the first period only, because of possible carry-over effects. Whenever possible, we used results from an intention-to-treat analysis. If we could not calculate effect sizes, we contacted the authors for additional data.

\section{Assessment of risk of bias in included studies}

Two review authors (SR and AR) independently assessed randomisation, blinding, and adequacy of analyses (Juni 2001). We resolved disagreements by consensus. We assessed two components of randomisation: generation of allocation sequences and concealment of allocation. We considered the generation adequate if it resulted in unpredictable allocation sequences; mechanisms considered adequate included random-number tables, computergenerated random numbers, minimisation, coin tossing, shuffling of cards, and drawing of lots. We considered allocation concealment adequate if the investigators responsible for patient selection were unable to deduce before allocation which treatment was next; methods considered adequate included central randomisation and sequentially numbered, sealed, opaque envelopes. We considered blinding of the patients adequate if the interventions were explicitly described as indistinguishable. We therefore considered sham interventions used to closely mimic the process of joint lavage adequate, but not mere placebo injections. We considered analyses adequate if all randomised patients were included in the analysis according to the intention-to-treat principle. In addition, we extracted the source of funding and distinguished between nonprofit and commercial funding bodies. Finally, we used GRADE to describe the quality of the overall body of evidence (Guyatt 2008; Higgins 2008), defined as the extent of confidence into the estimates of treatment benefits and harms. 


\section{Data synthesis}

We summarised continuous outcomes using standardised mean differences (SMD), with the differences in mean values at three months and one year after the intervention across treatment groups divided by the pooled standard deviation. An SMD of -0.20 standard deviation units can be considered a small difference between experimental and control group, an SMD of -0.50 a moderate, and -0.80 a large difference (Cohen 1988; Juni 2006). SMDs can be interpreted in terms of the percentage overlap of the experimental group's scores with scores of the control group. An SMD of -0.20 indicates an overlap in the distributions of pain or function scores in about $85 \%$ of cases, an SMD of -0.50 in approximately $67 \%$, and an SMD of -0.80 in about $50 \%$ of cases (Cohen 1988; Juni 2006). On the basis of a median pooled SD of $2.5 \mathrm{~cm}$ found in large-scale osteoarthritis trials that assessed pain using a $10 \mathrm{~cm}$ visual analogue scale (VAS) (Nuesch 2009), SMDs of $-0.20,-0.50$ and -0.80 correspond to approximate differences in pain scores between experimental and control groups of $0.5,1.25$, and 2.0 $\mathrm{cm}$ on a $10 \mathrm{~cm}$ VAS. We back transformed SMDs for function to a standardised WOMAC disability score (Bellamy 1995) ranging from 0 to 10 on the basis of a median pooled SD of 2.1 units observed in large-scale osteoarthritis (Nuesch 2009). We expressed binary outcomes as relative risks.

We used standard inverse-variance random-effects meta-analysis to combine the trials (DerSimonian 1986). We quantified heterogeneity between trials using the $\mathrm{I}^{2}$ statistic (Higgins 2003), which describes the percentage of variation across trials that is attributable to heterogeneity rather than to chance and the corresponding $\chi^{2}$ test. $\mathrm{I}^{2}$ values of $25 \%, 50 \%$ and $75 \%$ may be interpreted as low, moderate, and high between-trial heterogeneity, although the interpretation of $\mathrm{I}^{2}$ depends on the size and number of trials included (Rucker 2008). The association between trial size and treatment effects was investigated in funnel plots, plotting effect sizes on the vertical axis against their standard errors on the horizontal axis. We assessed asymmetry by the asymmetry coefficient: the difference in effect size per unit increase in standard error (Sterne 2001), which is mainly a surrogate for sample size. We performed analyses of the main outcome stratified by the following trial characteristics: type of intervention (arthroscopic versus non-arthroscopic lavage); type of control (placebo or sham intervention versus no intervention); concealment of allocation (adequate versus inadequate or unclear); blinding of patients (adequate versus inadequate or unclear); analysis in accordance with the intention-to-treat principle (yes versus no or unclear); trial size; funding; length of follow up, and differences in the use of co-interventions in the trial groups. A cut-off of 200 allocated patients was used to distinguish between small-scale and large-scale trials. We used univariable random-effects meta-regression models (Thompson 1999) to determine whether treatment effects were affected by these factors. In addition, we included the amount of lavage fluid used as a continuous variable at the trial level in a uni-variable meta-regression. Then, we converted SMDs of pain intensity and function to odds ratios (Chinn 2000) and derived numbers needed to treat (NNT) to cause one additional treatment response on pain or function as compared with control, and numbers needed to harm $(\mathrm{NNH})$ to cause one additional adverse outcome. We defined treatment response as a 50\% improvement in scores (Clegg 2006), which corresponds to an average decrease of 1.2 standard deviation units. Based on the median standardised pain intensity at baseline of 2.4 standard deviation units and the median standardised decrease in pain scores of 0.72 standard deviation units observed in large osteoarthritis trials (Nuesch 2009), we calculated that a median of $31 \%$ of patients in the control group would achieve an improvement of pain scores of $50 \%$ or more. This percentage was used as the control group response rate to calculate NNTs for treatment response on pain. Based on the median standardised WOMAC function score at baseline of 2.7 standard deviation units and the median standardised decrease in function scores of 0.58 standard deviation units (Nuesch 2009), $26 \%$ of patients in the control group would achieve a reduction in function of $50 \%$ or more. Again, this percentage was used as the control group response rate to calculate NNTs for treatment response on function. Median risks of 150 patients with adverse events per 1000 patient-years, four patients with serious adverse events per 1000 patient-years and 17 dropouts due to adverse events per 1000 patient-years observed in placebo groups in large osteoarthritis trials (Nuesch 2009) were used to calculate NNHs for safety outcomes. All P values are two-sided. We performed the data analysis in Review Manager version 5 (RevMan 2008) and STATA version 10.1 (STATA 2008).

\section{RES U L T S}

\section{Description of studies}

See: Characteristics of included studies; Characteristics of excluded studies; Characteristics of ongoing studies.

We identified 2073 potentially relevant references through our electronic searches (Figure 1) and considered 22 to be potentially eligible. We found two additional references through searches of conferences proceedings and abstracts. One trial would be eligible, but is ongoing (ISRCTN82192623, see Characteristics of ongoing studies). Seven RCTs met our inclusion criteria. We found three trials that performed joint lavage arthroscopically (Moseley 1996; Kalunian 2000; Moseley 2002). In two trials, joint lavage was performed without arthroscopy (Dawes 1987; Ravaud 1999). Tidal irrigation was performed in two trials (Ike 1992; Bradley 2002). Of the completed trials, six trials used a parallel group and one a $2 \times 2$ factorial design (Ravaud 1999), assigning 50\% of the participants to intra-articular corticosteroid injections. 
Figure I. Study flow chart

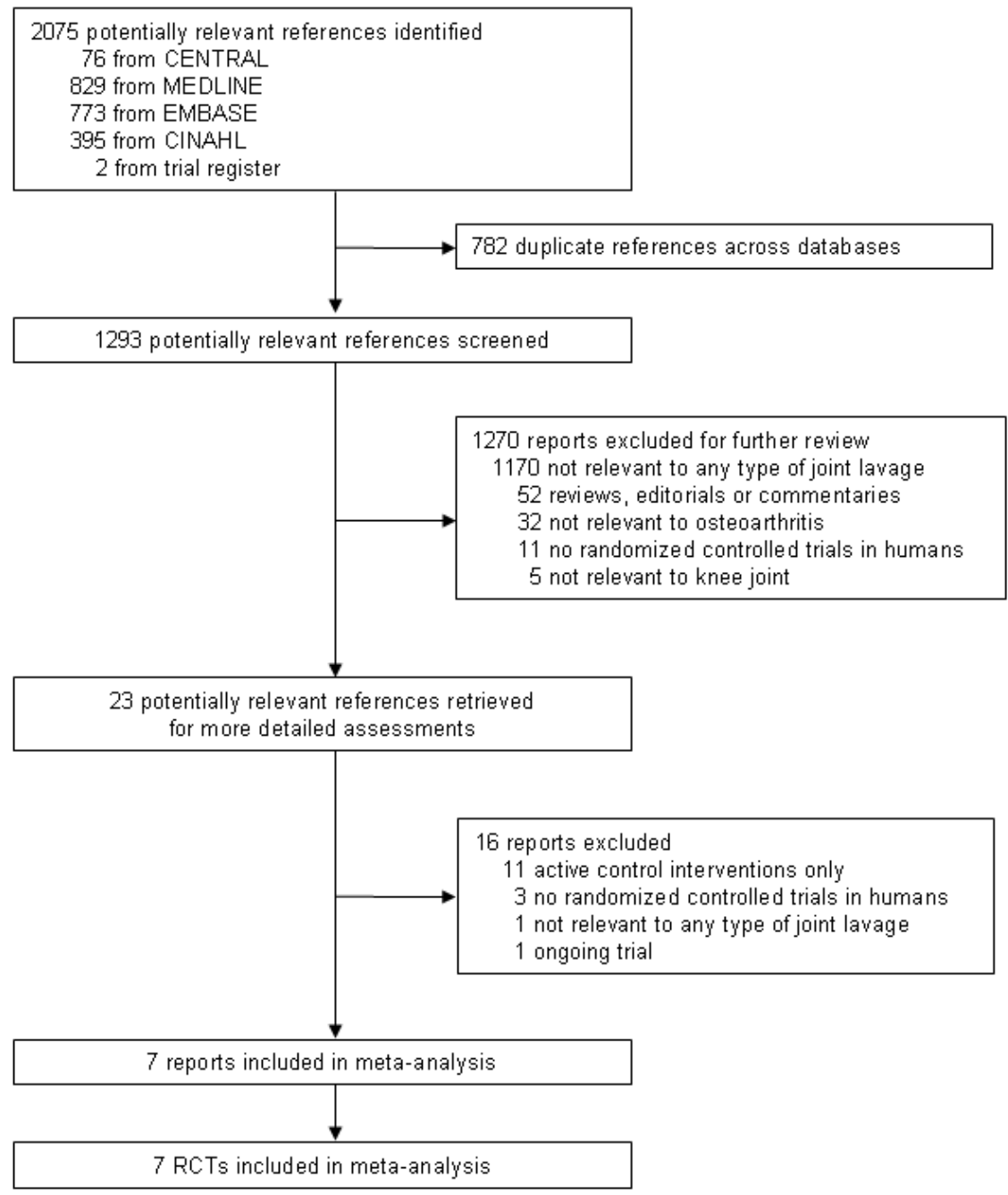


Four trials used a formal sham intervention to closely mimic the process of joint lavage (Moseley 1996; Kalunian 2000; Bradley 2002; Moseley 2002). Moseley 1996, Bradley 2002, and Moseley 2002 used sham procedures, two with incisions but without advancing instrument or applying intra-articular fluids (Moseley 1996; Moseley 2002 ), one with incisions, advancing the instruments to the joint capsule without perforating it (Bradley 2002) and one with incisions, advancing the instruments through the joint capsule and application of a small amount of intraarticular irrigation fluid of $250 \mathrm{ml}$ (Kalunian 2000). Two trials used placebo saline injections (Dawes 1987; Ravaud 1999), and one trial used a non-intervention control receiving standard conservative care (Ike 1992). In all trials, joint lavage and control intervention were performed only once, but different amounts of irrigation fluid were used, ranging from 1,000 ml (Ike 1992; Ravaud 1999; Bradley 2002) to 10,000 ml (Moseley 1996; Moseley 2002).

The median follow-up duration was six months, ranging from three months to two years. All trials provided results for our main time point of assessment at three months. Three trials had a long follow-up duration of at least one year (Kalunian 2000; Bradley 2002; Moseley 2002). The median average age of included patients was 59.5 years (range 46 to 67), and the median percentage of females was $56 \%$ (range $0 \%$ to $69 \%$ ). The mean duration of symptoms was reported in three trials and ranged from 2.7 to 10.6 years.

\section{Risk of bias in included studies}

Figure 2 summarises the methodological characteristics and sources of funding of included trials. None of the trials reported both adequate sequence generation and allocation concealment. Two trials reported adequate sequence of generation (Ravaud 1999; Kalunian 2000), and three trials reported adequate allocation concealment (Moseley 1996; Bradley 2002; Moseley 2002). In other trials the method of patient allocation remained unclear. Four trials were described as double blind, using a sham intervention to blind the patients (Moseley 1996; Kalunian 2000; Bradley 2002; Moseley 2002). In the other trials, blinding of patients was questionable because placebo injections were used as described above, which were distinguishable from experimental interventions (Dawes 1987; Ravaud 1999), and in one trial no attempt was made to blind patients (Ike 1992). Blinding of physicians was not deemed possible. Two trials analysed pain and function outcome according to the intention-to-treat principle (Ravaud 1999; Bradley 2002). Two trials did not report the number of patients excluded from the analysis (Dawes 1987; Kalunian 2000). In the remaining three trials (Ike 1992; Moseley 1996; Moseley 2002), exclusions of patients ranged from $3.3 \%$ to $33.3 \%$ in experimental and from $6.7 \%$ to $26.3 \%$ in control groups. None of the trials reached our prespecified cut-off of 200 allocated patients to distinguish between small- and large-scale trials. 
Figure 2. Methodological characteristics and source of funding of included trials. (+) indicates low risk of bias, (?) unclear and (-) a high risk of bias on a specific item.

\begin{tabular}{|c|c|c|c|c|c|c|c|c|c|c|}
\hline & 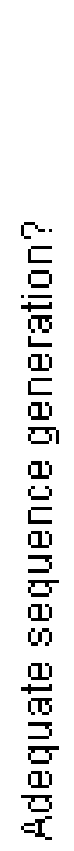 & 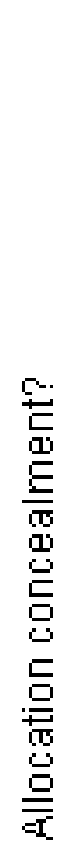 & 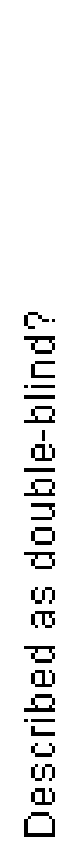 & 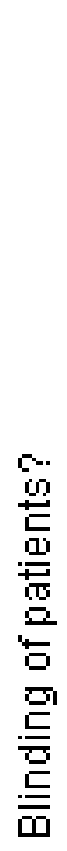 & 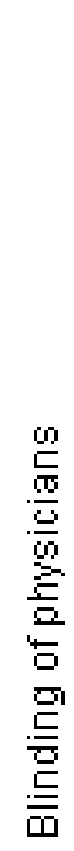 & 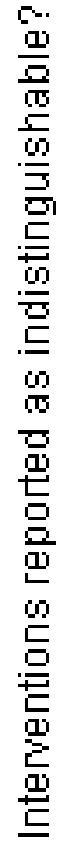 & 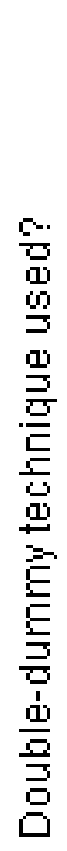 & 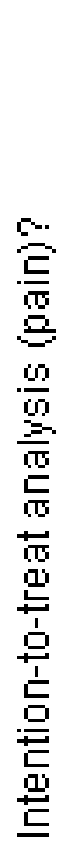 & 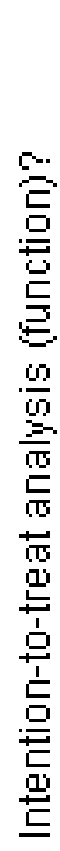 & 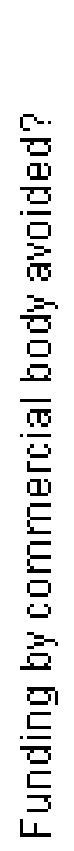 \\
\hline \multicolumn{11}{|l|}{ Bradley 2002} \\
\hline Dawes 1987 & $?$ & $?$ & & $?$ & & & & $?$ & $?$ & $?$ \\
\hline Ike 1992 & $?$ & $?$ & & & & & & & & \\
\hline Kalunian 2000 & + & $?$ & & & & & & $?$ & $?$ & \\
\hline Moseley 1996 & $?$ & + & + & & & ! & & & & + \\
\hline Moseley 2002 & $?$ & + & & & & & & & & + \\
\hline Ravaud 1999 & + & $?$ & & & & & & & & \\
\hline
\end{tabular}


Five trials reported a primary outcome (Ike 1992; Ravaud 1999; Kalunian 2000; Bradley 2002; Moseley 2002). None of these trials explicitly reported the primary outcome to be prespecified in the protocol. Four trials reported a sample size calculation for this primary outcome (Ike 1992; Kalunian 2000; Bradley 2002; Moseley 2002). Two trials reported financial support by both commercial and non-profit organisations (Ravaud 1999; Kalunian 2000). Two trials reported financial support by non-commercial organisations only (Bradley 2002; Moseley 2002), and one trial reported financial support by a commercial body only (Ike 1992).

For the effectiveness outcomes, pain, and function, the quality of the evidence (Guyatt 2008) was classified as low in view of the high risk of bias in the included trials and the high heterogeneity between trials (Summary of findings for the main comparison). For adverse event and serious adverse event outcomes, the quality of the evidence (Guyatt 2008) was classified as very low because of the small number of trials reporting the outcomes and the small number of serious adverse events which made estimates impossible (Summary of findings for the main comparison).

\section{Effects of interventions}

See: Summary of findings for the main comparison

\section{Primary outcomes}

\section{Knee pain}

Seven trials including 275 patients in experimental groups and 292 patients in control groups contributed to the analyses of knee pain. Figure 3 presents results of the analysis, overall and stratified according to the type of lavage. In the overall analysis, joint lavage was not more effective in pain reduction than control interventions (SMD $-0.11,95 \% \mathrm{CI}-0.42$ to 0.21 ). This corresponds to a difference in pain scores of $0.3 \mathrm{~cm}$ on a $10 \mathrm{~cm}$ VAS between joint lavage and control intervention, and to a difference in improvement from baseline of 5\% (95\% CI $-8 \%$ to $18 \%$ ), respectively (Summary of findings for the main comparison). An $\mathrm{I}^{2}$ of $65 \%$ indicated a moderate to large degree of between-trial heterogeneity (P for heterogeneity $=0.009)$. A visual inspection of the funnel plot suggested some degree of asymmetry, with smaller, more imprecise trials showing less beneficial results than larger trials (asymmetry coefficient $1.43,95 \%$ CI -1.68 to 4.54 ), but the test for asymmetry provided little evidence for asymmetry ( $\mathrm{P}=$ 0.57) (Figure 4).

Figure 3. Forest plot of 7 trials comparing the effects of any type of joint lavage and control interventions on knee pain after 3 months. Values on $x$-axis denote standardised mean differences (SMDs). The plot is stratified according to type of joint lavage.

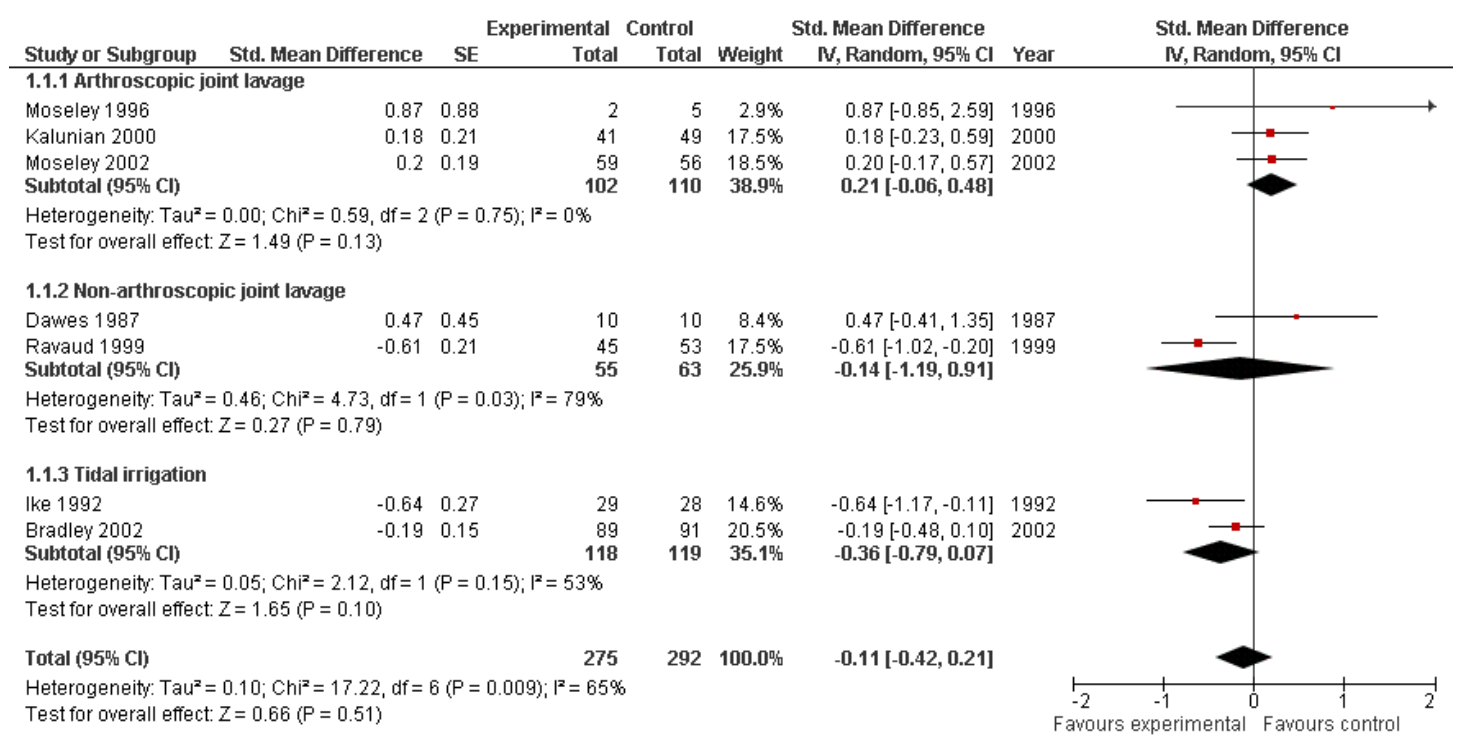


Figure 4. Funnel plot for effects on knee pain.

Numbers on $x$-axis refer to SMDs, on y-axis to standard errors of SMDs.

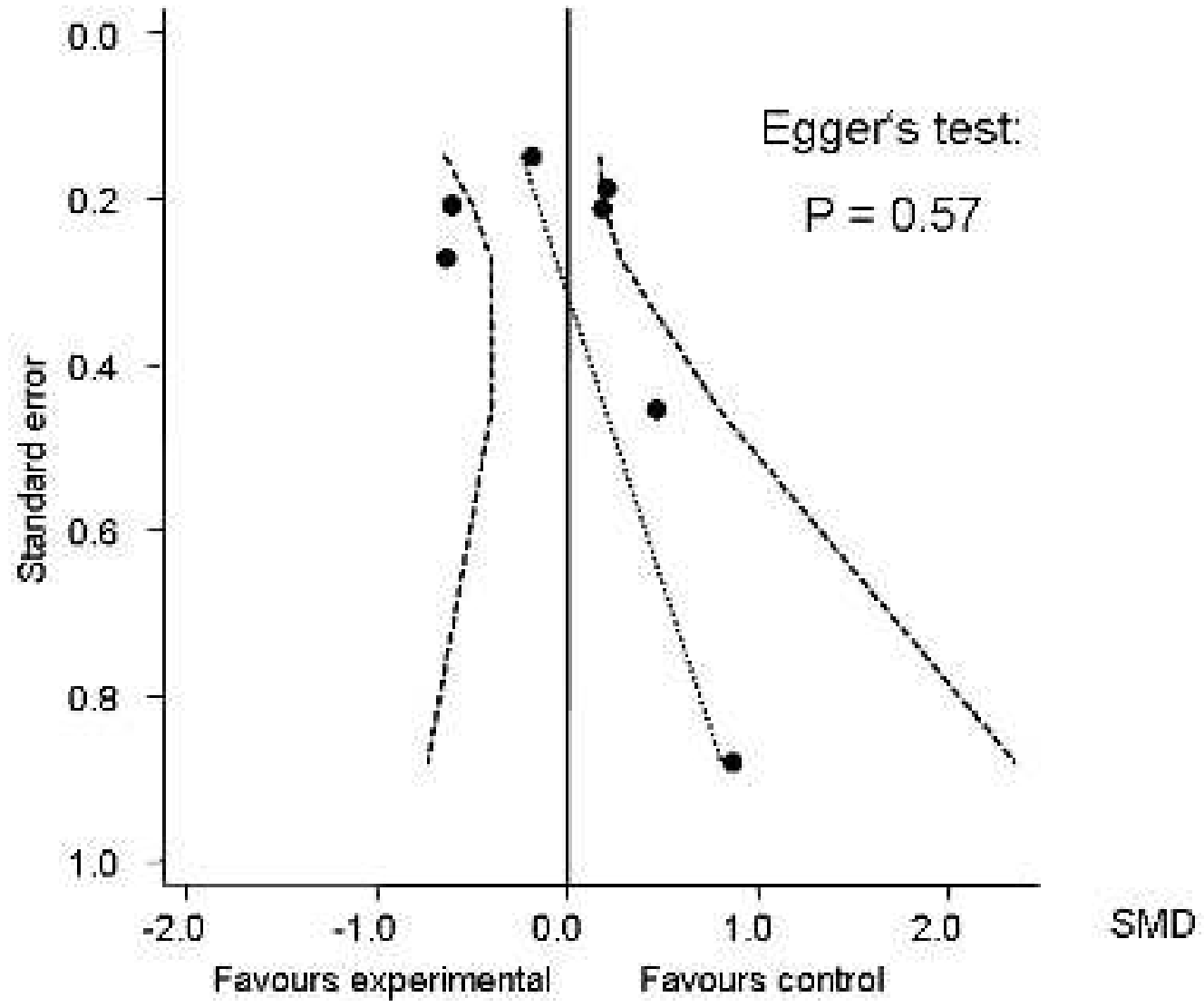

Figure 3 and Table 1 indicate that estimates of effect sizes varied to some degree depending on the type of lavage. The largest effect size was found in tidal irrigation (SMD $-0.36,95 \%$ CI -0.78 to $0.07 ; 2$ trials), followed by non-arthroscopic joint lavage with a small effect size (SMD -0.15, 95\% CI - 1.19 to $0.90 ; 2$ trials), and arthroscopic joint lavage with a trend towards a small harmful effect (SMD 0.21, 95\% CI - 0.06 to $0.48 ; 3$ trials). The confidence intervals were wide, however, and a test for interaction between benefit and type of lavage was non-significant $(P=0.27)$. In the additional stratified analyses presented in Table 1, we found some evidence that the effect size decreases with an increase of the extent and credibility of patient blinding. Figure 5 graphically displays this analysis. There appeared to be a linear trend, with trials with a credible sham intervention showing a null effect of joint lavage (SMD 0.06, 95\% CI -0.21 to 0.32), trials with a placebo injection

showing a small benefit on average (SMD -0.14, 95\% CI -1.19 to 0.91 ), and the trial with a non-intervention control showing a moderate to large benefit (SMD -0.64. 95\% CI -1.17 to -0.11). The $P$ value for trend between extent of credibility of the control intervention and treatment benefit was 0.09 . We found little evidence for an association of SMDs with allocation concealment, blinding of patients, intention-to-treat analysis, funding by noncommercial body, and use of analgesic co-interventions. None of the trials had a sample size above 200 patients; therefore we could not assess the impact of this characteristic on estimated treatment effects. In an additional uni-variable meta-regression analysis, we did not find an association between the amount of lavage fluid used and effect size (decrease in benefit per $1000 \mathrm{ml}$ increase in volume of 0.07 SMDs, $95 \% \mathrm{CI}-0.03$ to $0.17, \mathrm{P}=0.13$ ). 
Figure 5. Forest plot of 7 trials comparing the effects of any type of joint lavage and control interventions on knee pain after 3 month, stratified according to type of control interventions. Values on $x$-axis denote SMDs.

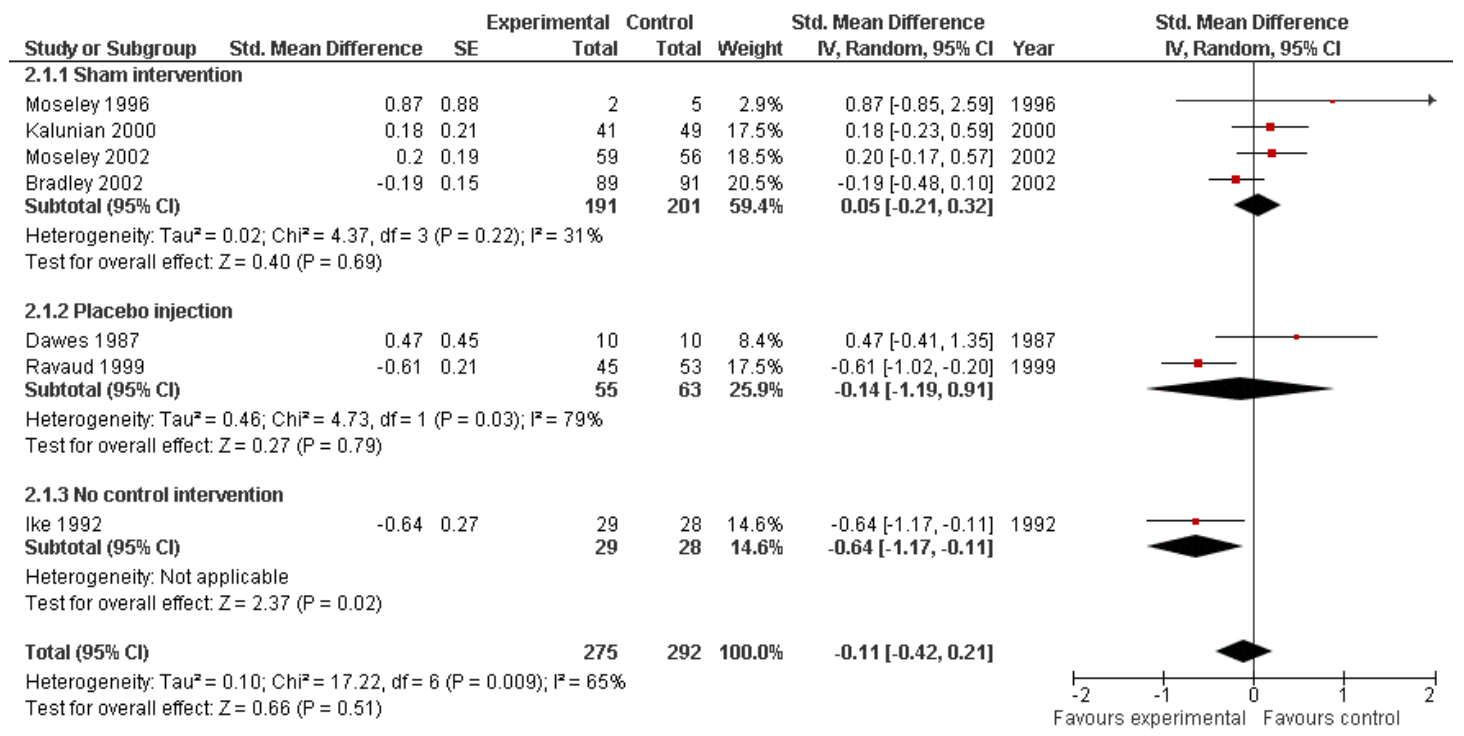

Table 1. Stratified analysis: pain

\begin{tabular}{|c|c|c|c|c|c|c|}
\hline Variable & $\begin{array}{l}\text { Number of } \\
\text { comparisons }\end{array}$ & $\begin{array}{l}\text { Number of pa- } \\
\text { tients in experi- } \\
\text { mental group }\end{array}$ & $\begin{array}{l}\text { Number of pa- } \\
\text { tients in control } \\
\text { group }\end{array}$ & Pain intensity & Heterogeneity & $\begin{array}{l}\text { P-value for inter- } \\
\text { action }\end{array}$ \\
\hline & $\mathrm{n}$ & $\mathrm{n}$ & $\mathrm{n}$ & SMD (95\% CI) & $\mathrm{I}^{2}(\%)$ & \\
\hline Overall & 7 & 275 & 292 & $\begin{array}{l}-0.11 \quad(-0.42 \text { to } \\
0.21)\end{array}$ & $65 \%$ & \\
\hline
\end{tabular}

Type of joint

0.27

lavage

\begin{tabular}{|c|c|c|c|c|}
\hline $\begin{array}{l}\text { Arthroscopic } \\
\text { nt lavage }\end{array}$ & 3 & 102 & 110 & $\begin{array}{l}0.21 \quad(-0.06 \text { to } \\
0.48)\end{array}$ \\
\hline
\end{tabular}

\begin{tabular}{l|l|l|l|l}
\hline $\begin{array}{c}\text { Non-arthro- } \\
\text { scopic joint } \\
\text { lavage }\end{array}$ & 2 & 55 & 63 & $\begin{array}{c}-0.15 \quad(-1.19 \text { to } 78 \% \\
0.90)\end{array}$ \\
\hline Tidal irrigation & 2 & 118 & 119 & $\begin{array}{c}-0.36 \quad(-0.78 \text { to } \\
0.07)\end{array}$ \\
\hline
\end{tabular}

Type of control

$0.09^{*}$ intervention 
Table 1. Stratified analysis: pain (Continued)

\begin{tabular}{|c|c|c|c|c|c|c|}
\hline $\begin{array}{l}\text { Sham interven- } \\
\text { tion }\end{array}$ & 4 & 191 & 201 & $\begin{array}{l}0.06 \quad(-0.21 \text { to } \\
0.32)\end{array}$ & $32 \%$ & \\
\hline $\begin{array}{l}\text { Placebo injec- } \\
\text { tion }\end{array}$ & 2 & 55 & 63 & $\begin{array}{l}-0.15 \quad(-1.19 \text { to } \\
0.90)\end{array}$ & $78 \%$ & \\
\hline $\begin{array}{l}\text { No control in- } \\
\text { tervention }\end{array}$ & 1 & 29 & 28 & $\begin{array}{l}-0.64(-1.17 \text { to }- \\
0.10)\end{array}$ & N/A & \\
\hline $\begin{array}{l}\text { Allocation con- } \\
\text { cealment }\end{array}$ & & & & & & 0.46 \\
\hline Adequate & 3 & 150 & 152 & $\begin{array}{lll}0.03 & (-0.34 \quad \text { to } \\
0.40) & & \end{array}$ & $46 \%$ & \\
\hline $\begin{array}{l}\text { Inadequate or } \\
\text { unclear }\end{array}$ & 4 & 125 & 140 & $\begin{array}{ll}-0.21 \quad(-0.72 \text { to } \\
0.31)\end{array}$ & $74 \%$ & \\
\hline $\begin{array}{l}\text { Blinding of pa- } \\
\text { tients }\end{array}$ & & & & & & 0.11 \\
\hline Adequate & 4 & 191 & 201 & $\begin{array}{l}0.06 \quad-0.21 \text { to } \\
0.32)\end{array}$ & $32 \%$ & \\
\hline $\begin{array}{l}\text { Inadequate or } \\
\text { unclear }\end{array}$ & 3 & 84 & 91 & $\begin{array}{ll}-0.38 & (-0.91 \text { to } \\
0.15) & \end{array}$ & $61 \%$ & \\
\hline $\begin{array}{l}\text { Intention-to- } \\
\text { treat analysis }\end{array}$ & & & & & & 0.21 \\
\hline Yes & 2 & 134 & 144 & $\begin{array}{lll}-0.37 & (-0.78 \text { to } \\
0.03) & & \end{array}$ & $63 \%$ & \\
\hline No & 5 & 141 & 148 & $\begin{array}{l}0.07 \quad(-0.33 \text { to } \\
0.47)\end{array}$ & $56 \%$ & \\
\hline $\begin{array}{l}\text { Number } \\
\text { of patients ran- } \\
\text { domised }\end{array}$ & & & & & & N/A \\
\hline$>200$ & 0 & & & & N/A & \\
\hline$<200$ & 7 & 275 & 292 & $\begin{array}{l}-0.11 \quad(-0.42 \text { to } \\
0.21)\end{array}$ & $65 \%$ & \\
\hline $\begin{array}{l}\text { Funding by non- } \\
\text { commercial } \\
\text { body avoided }\end{array}$ & & & & & & 0.46 \\
\hline
\end{tabular}


Table 1. Stratified analysis: pain (Continued)

\begin{tabular}{|c|c|c|c|c|c|c|}
\hline Yes & 3 & 150 & 152 & $\begin{array}{l}0.03 \quad(-0.34 \text { to } \\
0.40)\end{array}$ & $46 \%$ & \\
\hline No or unclear & 4 & 125 & 140 & $\begin{array}{ll}-0.21 & (-0.72 \text { to } \\
0.31) & \end{array}$ & $74 \%$ & \\
\hline $\begin{array}{l}\text { Use of analgesic } \\
\text { co-interventions }\end{array}$ & & & & & & 0.12 \\
\hline Yes & 4 & 222 & 228 & $\begin{array}{ll}-0.28 & (-0.65 \text { to } \\
0.09) & \end{array}$ & $73 \%$ & \\
\hline No or unclear & 3 & 53 & 64 & $\begin{array}{l}0.26 \quad(-0.11 \text { to } \\
0.63)\end{array}$ & $0 \%$ & \\
\hline
\end{tabular}

CI: confidence interval

* P value for trend

SMD: standardised mean difference

Three trials that included 187 patients in experimental groups and 193 patients in control groups contributed to the analyses of pain one year after the intervention (Kalunian 2000; Bradley 2002; Moseley 2002). All three trials used a sham procedure as their control intervention. We found little evidence for a pain reduction as compared with sham intervention (SMD - $0.10,95 \%$ CI -0.50 to $0.29, \mathrm{P}=0.60$, Figure 6 ), but between-trial heterogeneity was large $\left(\mathrm{I}^{2}=72 \%\right)$.

\section{Figure 6. Forest plot of 3 trials comparing the effects of any type of lavage and control interventions on} knee pain after one year. Values on $x$-axis denote SMDs.

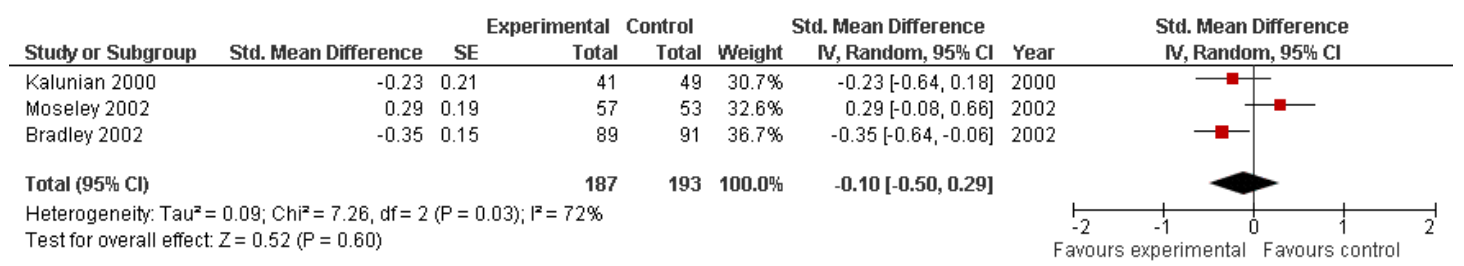

\section{Function}

Five trials including 263 patients in experimental groups and 272 patients in control groups contributed to the analyses of physical function. Figure 7 presents results of the analysis, overall and stratified according to the type of lavage. In the overall analysis, joint lavage showed no improvement in function compared to control interventions (SMD -0.10, 95\% CI -0.30 to 0.11 ). This corresponds to a difference in function scores of 0.4 units between joint lavage and control interventions on a standardised WOMAC 
disability scale ranging from 0 to 10 , and to a difference in improvement from baseline of $7 \%$ ( $95 \%$ CI $0 \%$ to $15 \%)$, respectively (Summary of findings for the main comparison). An $\mathrm{I}^{2}$ of $28 \%$ indicated a small degree of between-trial heterogeneity ( $\mathrm{P}$ for heterogeneity $=0.24)$. A visual inspection of the funnel plot suggested little asymmetry, with smaller, more imprecise trials showing less beneficial results than larger trials (asymmetry coefficient 3.19 (95\% CI -5.98 to 12.37$)$, but the test for asymmetry provided little evidence for asymmetry $(\mathrm{P}=0.37$ ) (Figure 8$)$.

Figure 7. Forest plot of 5 trials comparing the effects of any type of joint lavage and control interventions on function after 3 month. Values on x-axis denote SMDs. The plot is stratified according to type of joint lavage. .

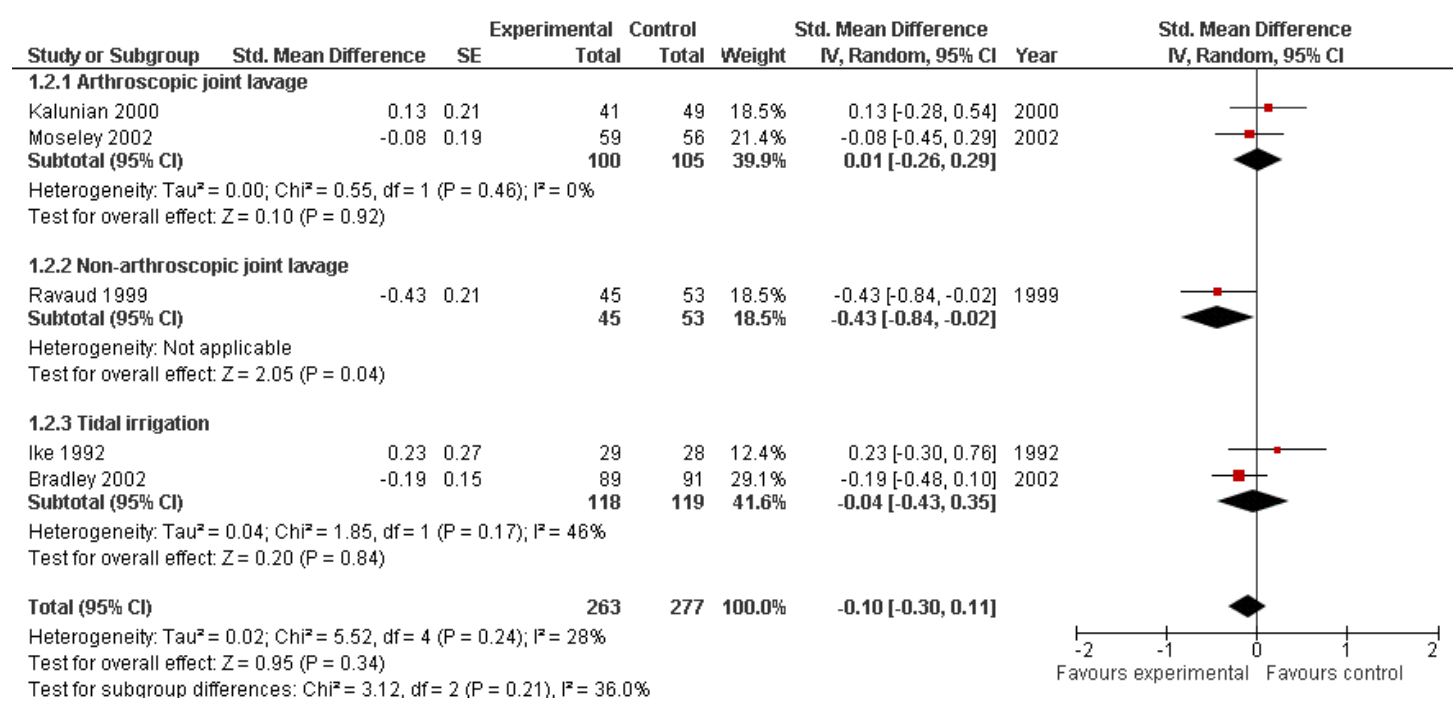


Figure 8. Funnel plot for effects on knee function. Numbers on $x$-axis refer to SMDs, on y-axis to standard errors of SMDs.

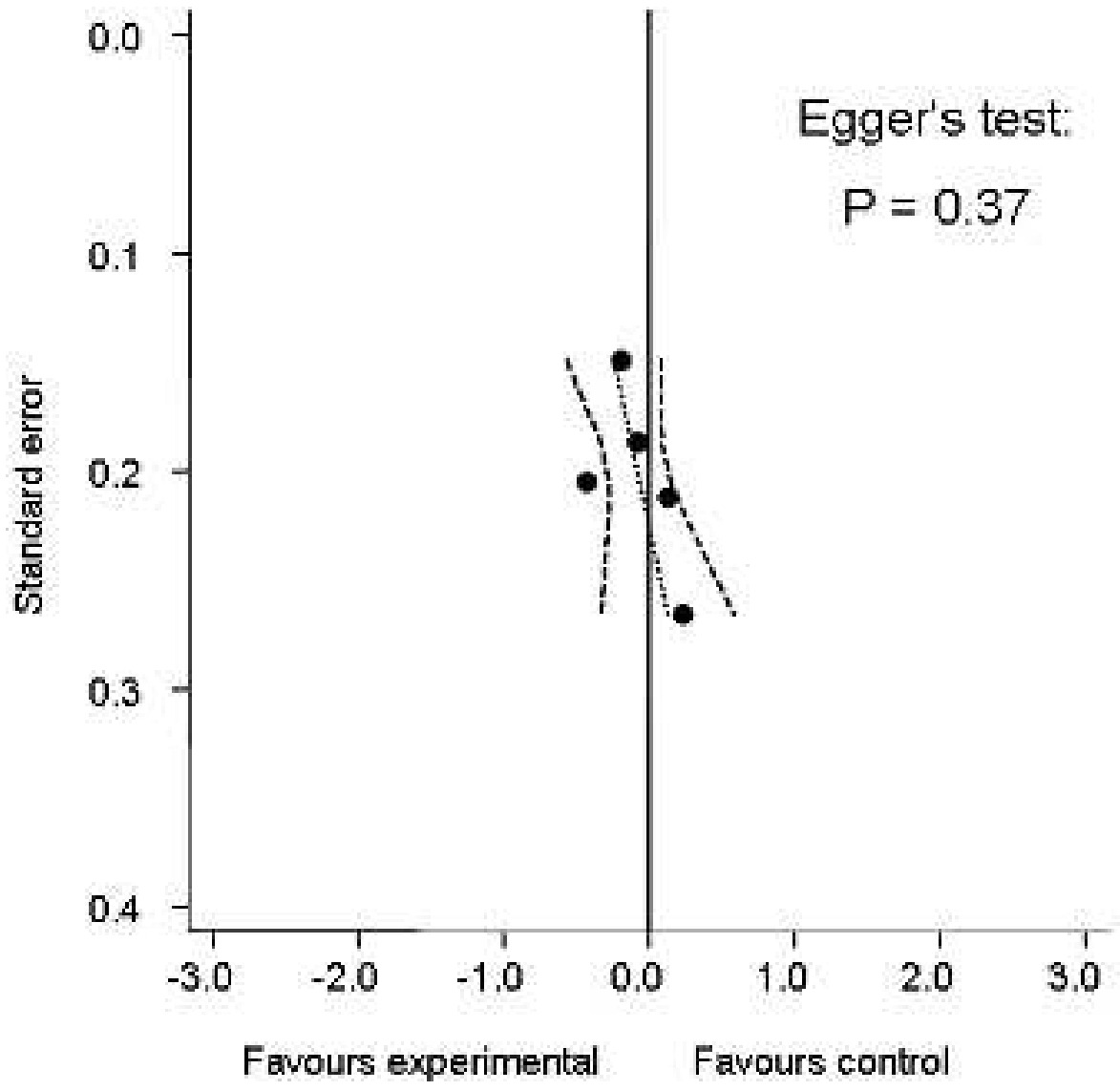

Figure 7 and Table 2 indicate that estimates of effect sizes varied to some degree depending on the type of lavage. The largest effect size was found in non-arthroscopic joint lavage (SMD - $0.43,95 \%$ CI 0.84 to $-0.02 ; 1$ trial). Arthroscopic joint lavage and tidal irrigation showed no benefit, with effect sizes of 0.01 for arthroscopic joint lavage ( $95 \%$ CI -0.26 to $0.29 ; 2$ trials) and -0.04 for tidal irrigation (95\% CI -0.43 to $0.35 ; 2$ trials). The confidence intervals were wide and a test for interaction between type of lavage and treatment benefit negative $(P=0.43)$. Table 2 presents additional results from stratified analyses, with some degree of variation of effect sizes across strata, but negative tests for interaction throughout. As for pain, we did not find an association between the amount of lavage fluid used and effect size in an additional uni-variable meta-regression analysis (decrease in benefit per $1000 \mathrm{ml}$ increase in volume of 0.01 SMDs, $95 \% \mathrm{CI}-0.10$ to $0.12, \mathrm{P}=0.81$ ). 
Table 2. Stratified analysis: function

\begin{tabular}{|c|c|c|c|c|c|c|}
\hline Variable & $\begin{array}{l}\text { Number of } \\
\text { comparisons }\end{array}$ & $\begin{array}{l}\text { Number of pa- } \\
\text { tients in experi- } \\
\text { mental group }\end{array}$ & $\begin{array}{l}\text { Number of pa- } \\
\text { tients in control } \\
\text { group }\end{array}$ & Function & Heterogeneity & $\begin{array}{l}\text { P-value for inter- } \\
\text { action }\end{array}$ \\
\hline & $\mathrm{n}$ & $\mathrm{n}$ & $\mathrm{n}$ & SMD $(95 \% \mathrm{CI})$ & $\mathrm{I}^{2}(\%)$ & \\
\hline Overall & 5 & 263 & 277 & $\begin{array}{l}-0.10 \quad(-0.30 \text { to } \\
0.11)\end{array}$ & $28 \%$ & \\
\hline $\begin{array}{l}\text { Type of joint } \\
\text { lavage }\end{array}$ & & & & & & 0.43 \\
\hline $\begin{array}{l}\text { Arthroscopic } \\
\text { joint lavage }\end{array}$ & 2 & 100 & 105 & $\begin{array}{l}0.01 \quad(-0.26 \text { to } \\
0.29)\end{array}$ & $0 \%$ & \\
\hline \begin{tabular}{l}
\multicolumn{2}{c}{ Non-arthro- } \\
scopic joint \\
lavage
\end{tabular} & 1 & 45 & 53 & $\begin{array}{l}-0.43(-0.83 \text { to }- \\
0.03)\end{array}$ & N/A & \\
\hline Tidal irrigation & 2 & 118 & 119 & $\begin{array}{l}-0.04 \quad(-0.44 \text { to } \\
0.36)\end{array}$ & $48 \%$ & \\
\hline $\begin{array}{l}\text { Type of control } \\
\text { intervention }\end{array}$ & & & & & & $0.79 *$ \\
\hline $\begin{array}{l}\text { Sham interven- } \\
\text { tion }\end{array}$ & 3 & 189 & 196 & $\begin{array}{ll}-0.08 & (-0.28 \text { to } \\
0.12) & \end{array}$ & $0 \%$ & \\
\hline $\begin{array}{l}\text { Placebo injec- } \\
\text { tion }\end{array}$ & 1 & 45 & 53 & $\begin{array}{l}-0.43(-0.83 \text { to }- \\
0.03)\end{array}$ & N/A & \\
\hline $\begin{array}{l}\text { No control in- } \\
\text { tervention }\end{array}$ & 1 & 29 & 28 & $\begin{array}{l}0.23 \quad(-0.29 \text { to } \\
0.75)\end{array}$ & N/A & \\
\hline $\begin{array}{l}\text { Allocation con- } \\
\text { cealment }\end{array}$ & & & & & & 0.73 \\
\hline Adequate & 2 & 148 & 147 & $\begin{array}{l}-0.15 \quad(-0.38 \text { to } \\
0.08)\end{array}$ & $0 \%$ & \\
\hline $\begin{array}{l}\text { Inadequate or } \\
\text { unclear }\end{array}$ & 3 & 115 & 130 & $\begin{array}{l}-0.04 \quad(-0.45 \text { to } \\
0.37)\end{array}$ & $62 \%$ & \\
\hline $\begin{array}{l}\text { Blinding of pa- } \\
\text { tients }\end{array}$ & & & & & & 0.75 \\
\hline Adequate & 3 & 189 & 196 & $\begin{array}{ll}-0.08 & (-0.28 \text { to } \\
0.12) & \end{array}$ & $0 \%$ & \\
\hline
\end{tabular}


Table 2. Stratified analysis: function (Continued)

\begin{tabular}{|c|c|c|c|c|c|c|}
\hline $\begin{array}{l}\text { Inadequate or } \\
\text { unclear }\end{array}$ & 2 & 74 & 81 & $\begin{array}{l}-0.12 \quad(-0.76 \text { to } \\
0.53)\end{array}$ & $74 \%$ & \\
\hline $\begin{array}{l}\text { Intention-to- } \\
\text { treat analysis }\end{array}$ & & & & & & 0.11 \\
\hline Yes & 2 & 134 & 144 & $\begin{array}{l}-0.27(-0.51 \text { to }- \\
0.04)\end{array}$ & $0 \%$ & \\
\hline No & 3 & 129 & 133 & $\begin{array}{l}0.06 \quad(-0.18 \text { to } \\
0.30)\end{array}$ & $0 \%$ & \\
\hline $\begin{array}{l}\text { Number } \\
\text { of patients ran- } \\
\text { domised }\end{array}$ & & & & & & N/A \\
\hline$>200$ & 0 & & & & N/A & \\
\hline$<200$ & 5 & 263 & 277 & $\begin{array}{l}-0.10 \quad(-0.30 \text { to } \\
0.11)\end{array}$ & $28 \%$ & \\
\hline $\begin{array}{l}\text { Funding by non- } \\
\text { commercial } \\
\text { body avoided }\end{array}$ & & & & & & 0.73 \\
\hline Yes & 2 & 148 & 147 & $\begin{array}{ll}-0.15 & (-0.38 \text { to } \\
0.08) & \end{array}$ & $0 \%$ & \\
\hline No or unclear & 3 & 115 & 130 & $\begin{array}{ll}-0.04 & (-0.45 \text { to } \\
0.37) & \end{array}$ & $62 \%$ & \\
\hline $\begin{array}{l}\text { Use of analgesic } \\
\text { co-interventions }\end{array}$ & & & & & & 0.34 \\
\hline Yes & 4 & 222 & 228 & $\begin{array}{ll}-0.15 & (-0.37 \text { to } \\
0.07) & \end{array}$ & $27 \%$ & \\
\hline No or unclear & 1 & 41 & 49 & $\begin{array}{l}0.13 \quad(-0.28 \text { to } \\
0.55)\end{array}$ & N/A & \\
\hline
\end{tabular}

${ }^{*} \mathrm{P}$ value for trend

Three trials that included 187 patients in experimental groups and 193 patients in control groups contributed to the analyses of function one year after intervention (Kalunian 2000; Bradley 2002; Moseley 2002). We found a trend towards more benefit in experimental groups compared to sham intervention (SMD -0.17, $95 \%$ CI -0.38 to $0.03, P=0.09$, Figure 9), with no between-trial heterogeneity $\left(\mathrm{I}^{2}=0 \%\right)$. 
Figure 9. Forest plot of 3 trials comparing the effects of any type of lavage and control interventions on function after one year. Values on x-axis denote SMDs.

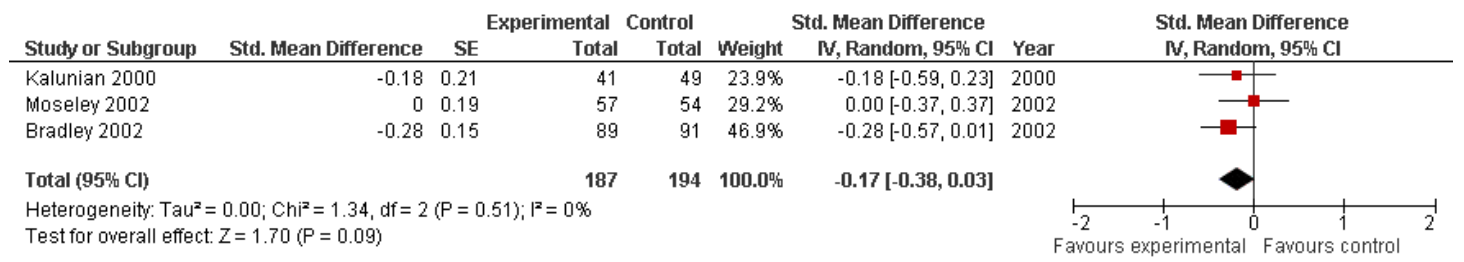

\section{Secondary outcomes}

The reporting of adverse events and drop-outs due to adverse events was unsatisfactory. Only one trial (Moseley 1996) reported one drop out due to an adverse event in the experimental group because of an acute psychiatric episode of a bipolar disorder. One trial (Ravaud 1999) reported that no serious adverse events had occurred.

\section{DISCUSSION}

\section{Summary of main results}

In our systematic review and meta-analysis of seven small trials, we found little evidence for a benefit of joint lavage in terms of pain relief and improvement of function in patients with knee osteoarthritis three months and one year after the intervention. For pain, estimates of effect sizes varied to some degree depending on the type of lavage, but this variation might be explained by differences in the credibility of control interventions: trials using sham interventions to closely mimic the process of joint lavage showed a clear null-effect. For functional improvement, we found a statistical trend towards a small benefit of lavage one year after the intervention, which may well be to chance alone.

Reporting on adverse events and drop-out rates was unsatisfactory, and we were not able to draw conclusions for these secondary outcomes. In view of the potentially serious adverse effects of an arthroscopy, including joint infection, effusion, hemarthrosis, deep vein thrombosis and thus prolonged hospitalisation, adequate reporting of safety outcomes is highly recommended. Since the accumulated number of serious adverse events may be too low in RCTs of the size observed in this review, alternative sources of safety information may be used, including large case series of consecutive patients or administrative databases.

\section{Quality of the evidence}

The quality of this review is limited by the small numbers of studies included, the low number of randomly assigned patients involved and the poor reporting quality. We aimed at including all possible types of joint lavage compared with all types of control interventions. The large heterogeneity observed after pooling all trials could therefore be related to either variation of effects with the type of lavage or with the type of control intervention. Our results indicate that the type of control intervention is a more likely source of variation: trials with credible sham interventions and adequate blinding of patients showed a null effect and benefits of the intervention increased with less stringent or lacking blinding of patients. This is consistent with the findings of a meta-analysis on determinants of the placebo effect in randomised controlled trials in osteoarthritis, which found that the pain relief increased when the placebo was applied invasively (Zhang 2008). A surgical sham intervention may be considered the most powerful placebo.

\section{Potential biases in the review process}

We based our review on a broad literature search. Even though we cannot exclude potential publication bias, it seems rather unlikely that we missed relevant trials (Egger 2003). Two review authors performed selection of trials and data extraction independently to minimise bias and transcription errors (Gøtzsche 2007; Tendal 2009). The use of different instruments to measure joint pain and function made it necessary to calculate SMDs as a common measure of effectiveness to ensure comparability between outcomes assessed with different instruments. Poor correlation or differences in responsiveness of different instruments may be a potential threat to the validity of results (Puhan 2006).

\section{Agreements and disagreements with other studies or reviews}

We are unaware of any systematic review or meta-analysis addressing the topic of our review. The most prominent trial included in our analysis was Moseley 2002. This trial allocated patients 
with knee osteoarthritis to one of three arms, arthroscopic lavage, arthroscopic debridement or a sham intervention, and found effects of both interventions to be null or slightly harmful. The trial was subsequently criticised because of baseline imbalances and its limited power (Laskin 2005). Our overall results are fully concordant with Moseley 2002's results however, and - in terms of the estimated effect of debridement - also recently confirmed by Kirkley 2008, who compared arthroscopic debridement with a non-intervention control in 178 patients and found no evidence of a benefit of debridement.

\section{A U THORS' CONCLUSIONS}

\section{Implications for practice}

Joint lavage does not result in a relevant benefit for patients with knee osteoarthritis in terms of pain relief or improvement of function. Insufficient numbers of patients have been studied to exclude the potential for serious adverse events such as joint infection, effusion, hemarthrosis, or deep vein thrombosis. Joint lavage should be discouraged in patients with osteoarthritis.

\section{Implications for research}

Despite the low number of trials, the relatively small number of patients randomised, and the low quality of the evidence overall, additional trials are difficult to justify. The benefit of joint lavage is small to minute and likely to be outweighed by safety concerns. RCTs in orthopedic surgery should be continuously advocated. The debate is ongoing, however, as to whether invasive sham interventions are ethically justified and should be seen as a gold standard for control groups in surgical trials (London 2003; Miller 2004). Even if invasive sham interventions may be debatable, the continued resistance of the orthopaedic field to perform adequately powered randomised multicenter trials to compare selected surgical interventions with conservative treatment is hard to justify.

\section{ACKNOWLEDGEMENTS}

We thank the Cochrane Musculoskeletal editorial team for valuable comments and Malcom Sturdy for database support.

\section{R E F E R E N C E S}

\section{References to studies included in this review}

\section{Bradley 2002 \{published data only\}}

Bradley JD, Heilman DK, Katz BP, Gsell P, Wallick JE, Brandt KD. Tidal irrigation as treatment for knee osteoarthritis: a shamcontrolled, randomized, double-blinded evaluation. Arthritis and Rheumatism 2002;46(1):100-8.

Dawes 1987 \{published data only\}

Dawes PT, Kirlew C, Haslock I. Saline washout for knee osteoarthritis: results of a controlled study. Clinical Rheumatology 1987;6(1):61-3.

Ike 1992 \{published data only\} Ike RW, Arnold WJ, Rothschild EW, Shaw HL. Tidal irrigation versus conservative medical management in patients with osteoarthritis of the knee: a prospective randomized study. Tidal Irrigation Cooperating Group. Journal of Rheumatology 1992;19 (5):772-9.

Kalunian 2000 \{published data only\} Kalunian KC, Moreland LW, Klashman DJ, Brion PH, Concoff $\mathrm{AL}$, Myers $\mathrm{S}$, et al.Visually-guided irrigation in patients with early knee osteoarthritis: a multicenter randomized, controlled trial. Osteoarthritis Cartilage 2000;8(6):412-8

Moseley 1996 \{published data only\} Moseley JB Jr, Wray NP, Kuykendall D, Willis K, Landon G. Arthroscopic treatment of osteoarthritis of the knee: a prospective, randomized, placebo-controlled trial. Results of a pilot study. American Journal of Sports Medicine 1996;24(1):28-34.
Moseley 2002 \{published data only\}

Moseley JB, O’Malley K, Petersen NJ, Menke TJ, Brody BA, Kuykendall DH, et al.A controlled trial of arthroscopic surgery for osteoarthritis of the knee. New England Journal of Medicine 2002; 347(2):81-8.

\section{Ravaud 1999 \{published data only\}}

Ravaud P, Moulinier L, Giraudeau B, Ayral X, Guerin C, Noel E, et al.Effects of joint lavage and steroid injection in patients with osteoarthritis of the knee: results of a multicenter, randomized, controlled trial. Arthritis and Rheumatism 1999;42(3):475-82.

\section{References to studies excluded from this review}

Arden 2008 \{published data only\}

Arden NK, Reading IC, Jordan KM, Thomas L, Platten H, Hassan $\mathrm{A}$, et al.A randomised controlled trial of tidal irrigation vs corticosteroid injection in knee osteoarthritis: the KIVIS Study. Osteoarthritis Cartilage 2008;16(6):733-9.

\section{Chang 1993 \{published data only\}}

Chang RW, Falconer J, Stulberg SD, Arnold WJ, Manheim LM Dyer AR. A randomized, controlled trial of arthroscopic surgery versus closed-needle joint lavage for patients with osteoarthritis of the knee. Arthritis and Rheumatism 1993;36(3):289-96.

Forster 2003 \{published data only\} Forster MC, Straw R. A prospective randomised trial comparing intra-articular Hyalgan injection and arthroscopic washout for knee osteoarthritis. Knee 2003;10(3):291-3. 
Frías 2004 \{published data only\}

Frías G, Caracuel MA, Escudero A, Rumbao J, Pérez-Gujo V, del Carmen Castro M, et al.Assessment of the efficacy of joint lavage versus joint lavage plus corticoids in patients with osteoarthritis of the knee. Current Medical Research and Opinion 2004;20(6):861-7.

Gibson 1992 \{published data only\}

Gibson JN, White MD, Chapman VM, Strachan RK. Arthroscopic lavage and debridement for osteoarthritis of the knee. Journal of Bone and Joint Surgery. British Volume 1992;74(4):534-7.

Hempfling 2007 \{published data only\}

Hempfling H. Intra-articular hyaluronic acid after knee arthroscopy: a two-year study. Knee Surgery, Sports Traumatology, Arthroscopy 2007;15(5):537-46.

Hubbard 1996 \{published data only\}

Hubbard MJ. Articular debridement versus washout for degeneration of the medial femoral condyle. A five-year study. Journal of Bone and Joint Surgery. British Volume 1996;78:217-9.

Jayaram 2006 \{published data only\} Jayaram M, Kumar P, Singh GK, Karn N. Role of arthroscopic lavage in the treatment of osteoarthritis. Journal of Orthopaedics 2006; Vol. 3, issue 4:e3.

Karkabi 2000 \{published data only\}

Karkabi S, Karpf R, Besser M. Curettage and lavage versus lavage only in arthroscopy of the knee. Journal of Bone and Joint Surgery British Volume 2000;82 Suppl 3:222-3.

Lennox 1998 \{published data only\}

Lennox IAC. The clinical and biological effects of arthroscopic washout. Journal of Bone and Joint Surgery. British Volume 1998;80 Suppl 1:99-100.

\section{Livesley 1991 \{published data only\}}

Livesley PJ, Doherty M, Needoff M, Moulton A. Arthroscopic lavage of osteoarthritic knees. Journal of Bone and Joint Surgery. British Volume 1991;73(6):922-6.

Merchan 1993 \{published data only\}

Merchan EC, Galindo E. Arthroscope-guided surgery versus nonoperative treatment for limited degenerative osteoarthritis of the femorotibial joint in patients over 50 years of age: a prospective comparative study. Arthroscopy 1993;9(6):663-7.

Smith 2003 \{published data only\}

Smith MD, Wetherall M, Darby T, Esterman A, Slavotinek J, Roberts-Thomson P, et al.A randomized placebo-controlled trial of arthroscopic lavage versus lavage plus intra-articular corticosteroids in the management of symptomatic osteoarthritis of the knee. Rheumatology 2003;42(12):1477-85.

Vad 2003 \{published data only\}

Vad VB, Bhat AL, Sculco TP, Wickiewicz TL. Management of knee osteoarthritis: knee lavage combined with hylan versus hylan alone. Archives of Physical Medicine and Rehabilitation 2003;84(5):634-7.

Ward 1998 \{published data only\}

Ward PJ, Ramos JL, Fernandez GN, Palazon J. A prospective randomised controlled trial of cannula versus arthroscopic lavage in patients with osteoarthritis of the knee. Journal of Bone and Joint Surgery. British Volume 1998;80 Suppl 1:46.

\section{References to ongoing studies}

\section{ISRCTN82192623 \{published data only\}}

ISRCTN82192623. Prospective randomised single blind trial comparing the effectiveness of combined arthroscopic washout and intra articular hyaluronan injection to intra articular hyaluronan injection and arthroscopic washout in isolation, for osteoarthritis of knee. http://www.controlled-trials.com/ISRCTN82192623/ 82192623 (accessed 24 November 2009).

\section{Additional references}

\section{Altman 1996}

Altman R, Brandt K, Hochberg M, Moskowitz R, Bellamy N, Bloch DA, et al.Design and conduct of clinical trials in patients with osteoarthritis: recommendations from a task force of the Osteoarthritis Research Society. Results from a workshop. Osteoarthritis Cartilage 1996;4(4):217-43.

\section{Bellamy 1995}

Bellamy N. Outcome measurement in osteoarthritis clinical trials. The Journal of Rheumatology. Supplement 1995;43:49-51.

\section{Bradley 2003}

Bradley JD. Joint irrigation as treatment for osteoarthritis. Current Rheumatology Reports 2003;5(1):20-6.

\section{Chinn 2000}

Chinn S. A simple method for converting an odds ratio to effect size for use in meta-analysis. Statistics in Medicine 2000;19(22): 3127-31.

Clegg 2006 Clegg DO, Reda DJ, Harris CL, Klein MA, O'Dell JR, Hooper $\mathrm{MM}$, et al.Glucosamine, chondroitin sulfate, and the two in combination for painful knee osteoarthritis. New England Journal of Medicine 2006;354(8):795-808.

\section{Cohen 1988}

Cohen J. Statistical power analysis for the behavioral sciences. 2nd Edition. Hillsdale, NJ: Lawrence Earlbaum Associates, 1988.

\section{DerSimonian 1986}

DerSimonian R, Laird N. Meta-analysis in clinical trials. Controlled Clinical Trials 1986;7(3):177-88.

\section{Dickersin 1994}

Dickersin K, Scherer R, Lefebvre C. Identifying relevant studies for systematic reviews. BMJ 1994;309(6964):1286-91.

Egger 2003

Egger M, Juni P, Bartlett C, Holenstein F, Sterne J. How important are comprehensive literature searches and the assessment of trial quality in systematic reviews? Empirical study. Health Technology Assessment (Winchester, England) 2003;7(1):1-76.

Guyatt 2008

Guyatt G, Oxman AD, Vist GE, Kunz R, Falck-Ytter Y, AlonsoCoello P, et al.GRADE: an emerging consensus on rating quality of evidence and strength of recommendations. BMJ 2008;336(7650): $924-6$.

Gøtzsche 2007

Gøtzsche PC, Hróbjartsson A, Maric K, Tendal B. Data extraction errors in meta-analyses that use standardized mean differences. JAMA 2007;298(4):430-7. 
Higgins 2003

Higgins JP, Thompson SG, Deeks JJ, Altman DG. Measuring inconsistency in meta-analyses. BMJ 2003;327(7414):557-60.

\section{Higgins 2008}

Higgins JPT, Green S (editors). Cochrane Handbook for Systematic Reviews of Interventions. Version 5.0.1. The Cochrane Collaboration, 2008.

Jackson 2003

Jackson RW, Dieterichs C. The results of arthroscopic lavage and debridement of osteoarthritic knees based on the severity of degeneration: a 4- to 6-year symptomatic follow-up. Arthroscopy 2003;19(1):13-20

\section{Juni 2001}

Juni P, Altman DG, Egger M. Systematic reviews in health care: assessing the quality of controlled clinical trials. BMJ 2001;323 (7303):42-6

\section{Juni 2006}

Juni P, Reichenbach S, Dieppe P. Osteoarthritis: rational approach to treating the individual. Best Practice and Research. Clinical Rheumatology 2006;20(4):721-40.

\section{Kirkley 2008}

Kirkley A, Birmingham TB, Litchfield RB, Giffin JR, Willits KR, Wong CJ, et al.A randomized trial of arthroscopic surgery for osteoarthritis of the knee. New England Journal of Medicine 2008; 359(11):1097-107.

\section{Laskin 2005}

Laskin RS, Ohnsorge JA. The role of arthroscopy: beneficial, placebo, or worse?. Orthopedics 2005;28(9):975-6.

\section{Laupattarakasem 2008}

Laupattarakasem W, Laopaiboon M, Laupattarakasem P, Sumananont C. Arthroscopic debridement for knee osteoarthritis. Cochrane Database of Systematic Reviews 2008, Issue 1. [DOI: 10.1002/14651858.CD005118.pub2]

\section{Livesley 1991}

Livesley PJ, Doherty M, Needoff M, Moulton A. Arthroscopic lavage of osteoarthritic knees. Journal of Bone and Joint Surgery. British Volume 1991;73(6):922-6.

\section{London 2003}

London AJ, Kadane JB. Sham surgery and genuine standards of care: can the two be reconciled?. The American Journal of Bioethics 2003;3(4):61-4.

\section{Miller 2004}

Miller FG. Sham surgery: an ethical analysis. Science and Engineering Ethics 2004;10(1):157-66.

\section{Nuesch 2009}

Nuesch E, Trelle S, Reichenbach S, Rutjes AWS, Burgi E, Scherer $M$, et al.The effects of the exclusion of patients from the analysis in randomised controlled trials: meta-epidemiological study. $B M J$ 2009;339:b3244

\section{Pham 2004}

Pham T, van der Heijde D, Altman RD, Anderson JJ, Bellamy N, Hochberg M, et al.OMERACT-OARSI initiative: Osteoarthritis Research Society International set of responder criteria for osteoarthritis clinical trials revisited. Osteoarthritis Cartilage 2004; 12(5):389-99.

\section{Puhan 2006}

Puhan MA, Soesilo I, Guyatt GH, Schunemann HJ. Combining scores from different patient reported outcome measures in metaanalyses: when is it justified?. Health and Quality of Life Outcomes 2006;4:94.

\section{Reichenbach 2007}

Reichenbach S, Sterchi R, Scherer M, Trelle S, Burgi E, Burgi U, et al.Meta-analysis: chondroitin for osteoarthritis of the knee or hip. Annals of Internal Medicine 2007;146(8):580-90.

\section{RevMan 2008}

The Nordic Cochrane Centre, The Cochrane Collaboration. Review Manager (RevMan). 5.0. Copenhagen: The Nordic Cochrane Centre, The Cochrane Collaboration, 2008.

\section{Rucker 2008}

Rucker G, Schwarzer G, Carpenter JR, Schumacher M. Undue reliance on $\mathrm{I}(2)$ in assessing heterogeneity may mislead. $B M C$ Medical Research Methodology 2008;8(1):79.

\section{STATA 2008}

StataCorp. STATA. 10.1. College Station, Texas: StataCorp, 2008.

\section{Sterne 2001}

Sterne JA, Egger M. Funnel plots for detecting bias in metaanalysis: guidelines on choice of axis. Journal of Clinical Epidemiology 2001;54(10):1046-55.

\section{Tendal 2009}

Tendal B, Higgins JP, Jüni P, Hróbjartsson A, Trelle S, Nüesch E, et al.Disagreements in meta-analyses using outcomes measured on continuous or rating scales: observer agreement study. BMJ 2009; 339:b3128. [DOI: 10.1136/bmj.b3128]

\section{Thompson 1999}

Thompson SG, Sharp SJ. Explaining heterogeneity in metaanalysis: a comparison of methods. Statistics in Medicine 1999;18 (20):2693-708.

\section{Zhang 2008}

Zhang W, Robertson J, Jones AC, Dieppe PA, Doherty M. The placebo effect and its determinants in osteoarthritis: meta-analysis of randomised controlled trials. Annals of the Rheumatic Diseases 2008;67(12):1716-23.

* Indicates the major publication for the study 
CHARACTERISTICS OF STUDIES

Characteristics of included studies [ordered by year of study]

Dawes 1987

\begin{tabular}{ll}
\hline Methods & $\begin{array}{l}\text { Randomised controlled trial } \\
\text { 2-arm parallel group design } \\
\text { Trial duration: } 12 \text { weeks } \\
\text { No power calculation reported } \\
\text { Funding by non-profit organisation: not reported }\end{array}$ \\
\hline Participants & $\begin{array}{l}20 \text { patients with knee OA were randomised } \\
\text { Number of females: } 12 \text { of } 20 \text { (60\%) } \\
\text { Average age: } 60 \text { years } \\
\text { Average BMI: not reported }\end{array}$ \\
\hline Interventions & $\begin{array}{l}\text { Experimental intervention: non-arthroscopic lavage (volume of irrigation fluid: } \\
2,000 m l) \\
\text { Control intervention: one saline injection } \\
\text { Analgesics allowed }\end{array}$ \\
\hline Outcomes & $\begin{array}{l}\text { Extracted pain outcome: pain on walking after } 12 \text { weeks } \\
\text { Extracted function outcome: } 25 \text {-yards walk time (seconds) after } 12 \text { weeks } \\
\text { Primary outcome: not reported }\end{array}$ \\
\hline Notes & \\
\hline
\end{tabular}

\section{Risk of bias}

\begin{tabular}{lll}
\hline Item & Authors' judgement & Description \\
\hline Adequate sequence generation? & Unclear & No information provided \\
\hline Allocation concealment? & Unclear & No information provided \\
\hline Described as double-blind? & No & No information provided \\
\hline Blinding of patients? & Unclear & \\
\hline Blinding of physicians? & No & \\
\hline $\begin{array}{l}\text { Interventions reported as indistinguish- } \\
\text { able? }\end{array}$ & No & \\
\hline $\begin{array}{l}\text { Double-dummy technique used? } \\
\text { Intention-to-treat analysis (pain)? }\end{array}$ & No & No information on exclusions available
\end{tabular}


Dawes 1987 (Continued)

\begin{tabular}{lll}
\hline Intention-to-treat analysis (function)? & Unclear & No information on exclusions available \\
\hline Funding by commercial body avoided? & Unclear & No information provided \\
\hline
\end{tabular}

\section{Ike 1992}

\begin{tabular}{|c|c|c|}
\hline Methods & \multicolumn{2}{|c|}{$\begin{array}{l}\text { Randomised controlled trial } \\
\text { 2-arm parallel group design } \\
\text { Trial duration: } 12 \text { weeks } \\
\text { Multicentre trial with } 15 \text { centres } \\
\text { Power calculation reported } \\
\text { Funding by non-profit organisation:not reported }\end{array}$} \\
\hline Participants & \multicolumn{2}{|c|}{$\begin{array}{l}77 \text { patients with knee OA were randomised } \\
\text { Number of females: } 43 \text { of } 77(56 \%) \\
\text { Average age: } 67 \text { years } \\
\text { Average BMI: not reported }\end{array}$} \\
\hline Interventions & \multicolumn{2}{|c|}{$\begin{array}{l}\text { Experimental intervention: tidal irrigation and standard conservative care (volume of } \\
\text { irrigation fluid:1,000ml) } \\
\text { Control intervention: standard conservative care } \\
\text { Treatment duration: } 12 \text { weeks for standard conservative care }\end{array}$} \\
\hline Outcomes & \multicolumn{2}{|c|}{$\begin{array}{l}\text { Extracted pain outcome: pain after walking } 50 \text {-foot after } 12 \text { weeks } \\
\text { Extracted function outcome: } 50 \text {-foot walk time (seconds) after } 12 \text { weeks } \\
\text { Primary outcome: pain scores (used for power calculation) }\end{array}$} \\
\hline \multicolumn{3}{|l|}{ Notes } \\
\hline \multicolumn{3}{|l|}{ Risk of bias } \\
\hline Item & Authors' judgement & Description \\
\hline Adequate sequence generation? & Unclear & No information provided \\
\hline Allocation concealment? & Unclear & No information provided \\
\hline Described as double-blind? & No & \\
\hline Blinding of patients? & No & \\
\hline Blinding of physicians? & No & \\
\hline $\begin{array}{l}\text { Interventions reported as indistinguish- } \\
\text { able? }\end{array}$ & No & \\
\hline Double-dummy technique used? & No & \\
\hline
\end{tabular}


Ike 1992 (Continued)

\begin{tabular}{l|l|l}
\hline Intention-to-treat analysis (pain)? & No & $\begin{array}{l}10 \text { of 39 patients excluded in experimental } \\
\text { group; } 10 \text { of 38 patients excluded in control } \\
\text { group }\end{array}$ \\
\hline Intention-to-treat analysis (function)? & No & $\begin{array}{l}10 \text { of 39 patients excluded in experimental } \\
\text { group; } 10 \text { of 38 patients excluded in control } \\
\text { group }\end{array}$ \\
\hline Funding by commercial body avoided? & No & Sponsor: Abbott Laboratories. \\
\hline
\end{tabular}

Moseley 1996

\begin{tabular}{ll}
\hline Methods & $\begin{array}{l}\text { Randomised controlled trial } \\
\text { 3-arm parallel group design } \\
\text { Trial duration: } 26 \text { weeks } \\
\text { Simple randomisation } \\
\text { No power calculation reported } \\
\text { Funding by non-profit organisation: not reported }\end{array}$ \\
\hline Participants & $\begin{array}{l}10 \text { patients with knee OA were randomised } \\
\text { Number of females: } 0 \text { of } 10 \text { (0\%) } \\
\text { Average age: } 46 \text { years } \\
\text { Average BMI: not reported }\end{array}$ \\
\hline Interventions & $\begin{array}{l}\text { Experimental intervention: arthroscopic lavage (volume of irrigation fluid: } 10,000 \text { ml) } \\
\text { Control intervention: sham arthroscopic lavage } \\
\text { Analgesics allowed }\end{array}$ \\
\hline Outcomes & $\begin{array}{l}\text { Extracted pain outcome: global pain after } 13 \text { weeks } \\
\text { Extracted function outcome: } 50 \text {-foot walk time (seconds) after } 13 \text { weeks } \\
\text { Primary outcome: not reported }\end{array}$ \\
\hline Notes & 1 trial arm (arthroscopic debridement) excluded from review \\
\hline
\end{tabular}

\section{Risk of bias}

\begin{tabular}{lll}
\hline Item & Authors' judgement & Description \\
\hline Adequate sequence generation? & Unclear & No information provided \\
\hline Allocation concealment? & Yes & \\
\hline Described as double-blind? & Yes & \\
\hline Blinding of patients? & Yes & \\
\hline Blinding of physicians? & No & \\
\hline
\end{tabular}


Moseley 1996 (Continued)

\begin{tabular}{|c|c|c|}
\hline $\begin{array}{l}\text { Interventions reported as indistinguish- } \\
\text { able? }\end{array}$ & Unclear & No information provided \\
\hline Double-dummy technique used? & No & \\
\hline Intention-to-treat analysis (pain)? & No & $\begin{array}{l}1 \text { of } 3 \text { patients excluded in experimental } \\
\text { group; } 0 \text { of } 5 \text { patients excluded in control } \\
\text { group }\end{array}$ \\
\hline Intention-to-treat analysis (function)? & No & $\begin{array}{l}1 \text { of } 3 \text { patients excluded in experimental } \\
\text { group; } 0 \text { of } 5 \text { patients excluded in control } \\
\text { group }\end{array}$ \\
\hline Funding by commercial body avoided? & Yes & $\begin{array}{l}\text { No author or related institution has re- } \\
\text { ceived any financial benefit from research } \\
\text { in this study }\end{array}$ \\
\hline
\end{tabular}

\section{Ravaud 1999}

\begin{tabular}{|c|c|}
\hline Methods & $\begin{array}{l}\text { Randomised controlled trial } \\
\text { 4-arm factorial design } \\
\text { Trial duration: } 24 \text { weeks } \\
\text { Randomisation stratified according to centre } \\
\text { Multicentre trial with } 16 \text { centres } \\
\text { No power calculation reported } \\
\text { Funding by non-profit organisation: Société Francaise du Rhumatologie; Direction de } \\
\text { la Recherche Clinique }\end{array}$ \\
\hline Participants & $\begin{array}{l}98 \text { patients with knee OA were randomised } \\
\text { Number of females: } 66 \text { of } 98(67 \%) \\
\text { Average age: } 65 \text { years } \\
\text { Average BMI: } 29 \mathrm{~kg} / \mathrm{m}^{2}\end{array}$ \\
\hline Interventions & $\begin{array}{l}\text { Experimental intervention: non-arthroscopic lavage (volume of irrigation fluid: } \\
1,000 \mathrm{ml} \text { ) } \\
\text { Control intervention: intra-articular placebo injection } \\
49 \text { patients }(50 \%) \text { allocated to intraarticular corticosteroid using a factorial design; no } \\
\text { evidence for an interaction between treatments } \\
\text { Analgesics allowed } \\
\text { Analgesic co-interventions were assessed }\end{array}$ \\
\hline Outcomes & $\begin{array}{l}\text { Extracted pain outcome: pain on activities other than walking after } 12 \text { weeks } \\
\text { Extracted function outcome: Lequesne OA index global score after } 12 \text { weeks } \\
\text { Primary outcome: percentage change in pain on VAS }\end{array}$ \\
\hline
\end{tabular}

Notes 
Ravaud 1999 (Continued)

\begin{tabular}{|c|c|c|}
\hline Item & Authors' judgement & Description \\
\hline Adequate sequence generation? & Yes & \\
\hline Allocation concealment? & Unclear & No information provided \\
\hline Described as double-blind? & No & \\
\hline Blinding of patients? & No & \\
\hline Blinding of physicians? & No & \\
\hline $\begin{array}{l}\text { Interventions reported as indistinguish- } \\
\text { able? }\end{array}$ & No & \\
\hline Double-dummy technique used? & No & \\
\hline Intention-to-treat analysis (pain)? & Yes & $\begin{array}{l}\text { All randomised patients included in the } \\
\text { analysis }\end{array}$ \\
\hline Intention-to-treat analysis (function)? & Yes & $\begin{array}{l}\text { All randomised patients included in the } \\
\text { analysis }\end{array}$ \\
\hline Funding by commercial body avoided? & No & Roussel Laboratories provided study drugs \\
\hline
\end{tabular}

Kalunian 2000

\begin{tabular}{ll}
\hline Methods & $\begin{array}{l}\text { Randomised controlled trial } \\
\text { 2-arm parallel group design } \\
\text { Trial duration: } 52 \text { weeks }\end{array}$ \\
& $\begin{array}{l}\text { Simple randomisation } \\
\text { Multicentre trial with } 4 \text { centres } \\
\text { Power calculation reported } \\
\text { Funding by non-profit organisation: American College of Rheumatology }\end{array}$ \\
\hline Participants & $\begin{array}{l}90 \text { patients with knee OA were randomised } \\
\text { Number of females: } 48 \text { of } 90 \text { (53\%) } \\
\text { Average age: } 59 \text { years } \\
\text { Average BMI: not reported }\end{array}$ \\
\hline Interventions & $\begin{array}{l}\text { Experimental intervention: arthroscopic lavage (volume of irrigation fluid: } 3,000 \mathrm{ml}) \\
\text { Control intervention: minimal irrigation arthroscopy (volume of irrigation fluid: } 250 \mathrm{ml})\end{array}$
\end{tabular}


Kalunian 2000 (Continued)

\begin{tabular}{|c|c|c|}
\hline Outcomes & \multicolumn{2}{|c|}{$\begin{array}{l}\text { Extracted pain outcome: global pain (VAS) after } 13 \text { weeks } \\
\text { Extracted function outcome: WOMAC disability subscore after } 13 \text { weeks } \\
\text { Primary outcome: WOMAC global score after } 12 \text { months }\end{array}$} \\
\hline \multicolumn{3}{|l|}{ Notes } \\
\hline \multicolumn{3}{|l|}{ Risk of bias } \\
\hline Item & Authors' judgement & Description \\
\hline Adequate sequence generation? & Yes & \\
\hline Allocation concealment? & Unclear & No information provided \\
\hline Described as double-blind? & Yes & \\
\hline Blinding of patients? & Yes & \\
\hline Blinding of physicians? & No & \\
\hline $\begin{array}{l}\text { Interventions reported as indistinguish- } \\
\text { able? }\end{array}$ & No & \\
\hline Double-dummy technique used? & No & \\
\hline Intention-to-treat analysis (pain)? & Unclear & No information on exclusions available \\
\hline Intention-to-treat analysis (function)? & Unclear & No information on exclusions available \\
\hline Funding by commercial body avoided? & No & $\begin{array}{l}\text { One co-author was affiliated with Eli Lilly } \\
\text { and Company, and the last author was af- } \\
\text { filiated with Genentech, Inc. }\end{array}$ \\
\hline
\end{tabular}

Bradley 2002

\begin{tabular}{ll}
\hline Methods & Randomised controlled trial \\
2-arm parallel group design & Trial duration: 52 weeks \\
Randomisation stratified according to K/L grade \\
Power calculation reported \\
Funding by non-profit organisation: NIH R01-AR-42165 \\
\hline Participants & 180 patients with knee OA were randomised \\
& $\begin{array}{l}\text { Number of females: } 124 \text { of } 180(69 \%) \\
\text { Average age: } 56 \text { years } \\
\text { Average BMI: not reported }\end{array}$ \\
\hline
\end{tabular}


Bradley 2002 (Continued)

\begin{tabular}{|c|c|c|}
\hline Interventions & \multicolumn{2}{|c|}{$\begin{array}{l}\text { Experimental intervention: tidal irrigation (volume of irrigation fluid: } 1,000 \mathrm{ml} \text { ) } \\
\text { Control intervention: sham tidal irrigation } \\
\text { Analgesics allowed } \\
\text { Analgesic co-interventions were assessed }\end{array}$} \\
\hline Outcomes & \multicolumn{2}{|c|}{$\begin{array}{l}\text { Extracted pain outcome: WOMAC pain subscore after } 12 \text { weeks } \\
\text { Extracted function outcome: WOMAC disability subscore after } 12 \text { weeks } \\
\text { Primary outcome: change in WOMAC pain and function subscores }\end{array}$} \\
\hline \multicolumn{3}{|l|}{ Notes } \\
\hline \multicolumn{3}{|l|}{ Risk of bias } \\
\hline Item & Authors' judgement & Description \\
\hline Adequate sequence generation? & Unclear & No information provided \\
\hline Allocation concealment? & Yes & \\
\hline Described as double-blind? & Yes & \\
\hline Blinding of patients? & Yes & \\
\hline Blinding of physicians? & No & \\
\hline $\begin{array}{l}\text { Interventions reported as indistinguish- } \\
\text { able? }\end{array}$ & No & \\
\hline Double-dummy technique used? & No & \\
\hline Intention-to-treat analysis (pain)? & Yes & $\begin{array}{l}\text { All randomised patients included in the } \\
\text { analysis }\end{array}$ \\
\hline Intention-to-treat analysis (function)? & Yes & $\begin{array}{l}\text { All randomised patients included in the } \\
\text { analysis }\end{array}$ \\
\hline Funding by commercial body avoided? & Yes & Funded by non-profit organisation \\
\hline
\end{tabular}


Moseley 2002

\begin{tabular}{l|l}
\hline Methods & $\begin{array}{l}\text { Randomised controlled trial } \\
\text { 3-arm parallel group design } \\
\text { Trial duration: } 103 \text { weeks } \\
\text { Randomisation stratified according to OA severity } \\
\text { Power calculation reported } \\
\text { Funding by non-profit organisation: Departement of Veterans Affairs }\end{array}$ \\
\hline Participants & $\begin{array}{l}180 \text { patients with knee OA were randomised } \\
\text { Number of females: } 13 \text { of } 180 \text { (7\%) } \\
\text { Average age: } 52 \text { years } \\
\text { Average BMI: not reported }\end{array}$ \\
\hline Interventions & $\begin{array}{l}\text { Experimental intervention: arthroscopic lavage (volume of irrigation fluid: } 10,000 \mathrm{ml}) \\
\text { Control intervention: sham arthroscopic lavage } \\
\text { Analgesics allowed } \\
\text { Analgesic co-interventions were assessed }\end{array}$ \\
\hline Outcomes & $\begin{array}{l}\text { Extracted pain outcome: knee specific pain scale after } 13 \text { weeks } \\
\text { Extracted function outcome: composite disability scores other than WOMAC after } 13 \\
\text { weeks } \\
\text { Primary outcome: knee specific pain scale }\end{array}$ \\
\hline Notes & 1 trial arm (arthroscopic debridement) excluded from review \\
\hline
\end{tabular}

\section{Risk of bias}

\begin{tabular}{|c|c|c|}
\hline Item & Authors' judgement & Description \\
\hline Adequate sequence generation? & Unclear & No information provided \\
\hline Allocation concealment? & Yes & \\
\hline Described as double-blind? & Yes & \\
\hline Blinding of patients? & Yes & \\
\hline Blinding of physicians? & No & \\
\hline $\begin{array}{l}\text { Interventions reported as indistinguish- } \\
\text { able? }\end{array}$ & No & \\
\hline Double-dummy technique used? & No & \\
\hline Intention-to-treat analysis (pain)? & No & $\begin{array}{l}2 \text { of } 61 \text { patients excluded in experimental } \\
\text { group; } 4 \text { of } 60 \text { patients excluded in control } \\
\text { group }\end{array}$ \\
\hline
\end{tabular}


Moseley 2002 (Continued)

\begin{tabular}{l|ll}
\hline Intention-to-treat analysis (function)? & No & $\begin{array}{l}2 \text { of } 61 \text { patients excluded in experimental } \\
\text { group; } 4 \text { of } 60 \text { patients excluded in control } \\
\text { group }\end{array}$ \\
\hline Funding by commercial body avoided? & Yes & Funded by non-profit organisation \\
\hline
\end{tabular}

BMI: body mass index

OA: osteoarthritis

VAS: visual analogue scale

\section{Characteristics of excluded studies [ordered by study ID]}

\begin{tabular}{|c|c|}
\hline Arden 2008 & Active control intervention (corticosteroid injection) \\
\hline Chang 1993 & Active control intervention (arthroscopic surgery) \\
\hline Forster 2003 & Active control intervention (hyaluronic acid injection) \\
\hline Frías 2004 & Active control intervention (corticosteroid injection) \\
\hline Gibson 1992 & Active control intervention (arthroscopic surgery) \\
\hline Hempfling 2007 & Active control intervention (hyaluronic acid injection) \\
\hline Hubbard 1996 & Active control intervention (arthroscopic surgery) \\
\hline Jayaram 2006 & No randomisation involved \\
\hline Karkabi 2000 & Active control intervention (arthroscopic surgery) \\
\hline Lennox 1998 & Active control intervention (physiotherapy) \\
\hline Livesley 1991 & No randomisation involved \\
\hline Merchan 1993 & Intervention was arthroscopic surgery and not lavage \\
\hline Smith 2003 & Active control intervention (corticosteroid injection) \\
\hline Vad 2003 & No randomisation involved \\
\hline Ward 1998 & Active control intervention (cannula lavage) \\
\hline
\end{tabular}


Characteristics of ongoing studies [ordered by study ID]

\section{ISRCTN82192623}

\begin{tabular}{|c|c|}
\hline Trial name or title & ISRCTN82192623 \\
\hline Methods & $\begin{array}{l}\text { Randomised controlled trial } \\
\text { 3-arm parallel group design } \\
\text { Trial duration: not reported } \\
\text { Power calculation reported } \\
\text { Funding by non-profit organisation: The North and South Bank Research and Development Consortium ( } \\
\text { UK) }\end{array}$ \\
\hline Participants & $\begin{array}{l}219 \text { patients with knee OA were anticipated } \\
\text { Number of females: not reported } \\
\text { Average age: not reported } \\
\text { Average BMI: not reported }\end{array}$ \\
\hline Interventions & $\begin{array}{l}\text { Experimental intervention: arthroscopic washout and intra-articular hyaluronan injection combined } \\
\text { Control intervention: intra-articular hyaluronan injection } \\
\text { Analgesics allowed: unknown }\end{array}$ \\
\hline Outcomes & $\begin{array}{l}\text { Extracted pain outcome: not provided } \\
\text { Extracted function outcome: not provided } \\
\text { Primary outcome: not reported }\end{array}$ \\
\hline Starting date & $01 / 01 / 2002$ \\
\hline Contact information & $\begin{array}{l}\text { Mr A Moshen } \\
\text { Orthopaedic Department } \\
\text { Hull Royal Infirmary } \\
\text { Anlaby Road } \\
\text { Hull } \\
\text { HU3 2JZ } \\
\text { United Kingdom } \\
\text { Tel +44(0)1482328 } 541 \\
\text { Email amr.mohsen@hey.nhs.uk }\end{array}$ \\
\hline Notes & Status at 18 December 2008: Completed \\
\hline
\end{tabular}

BMI: body mass index

OA: osteoarthritis 
DATA AND ANALYSES

Comparison 1. Joint lavage for osteoarthritis of the knee

\begin{tabular}{lcccc} 
Outcome or subgroup title & $\begin{array}{c}\text { No. of } \\
\text { studies }\end{array}$ & $\begin{array}{c}\text { No. of } \\
\text { participants }\end{array}$ & Statistical method & Effect size \\
\hline 1 Pain & 7 & 567 & Std. Mean Difference (Random, 95\% CI) & $-0.11[-0.42,0.21]$ \\
$\quad$ 1.1 Arthroscopic joint lavage & 3 & 212 & Std. Mean Difference (Random, 95\% CI) & $0.21[-0.06,0.48]$ \\
$\quad$ 1.2 Non-arthroscopic joint & 2 & 118 & Std. Mean Difference (Random, 95\% CI) & $-0.14[-1.19,0.91]$ \\
$\quad \begin{array}{l}\text { lavage } \\
\text { 1.3 Tidal irrigation }\end{array}$ & 2 & 237 & Std. Mean Difference (Random, 95\% CI) & $-0.36[-0.79,0.07]$ \\
2 Function & 5 & 540 & Std. Mean Difference (Random, 95\% CI) & $-0.10[-0.30,0.11]$ \\
$\quad$ 2.1 Arthroscopic joint lavage & 2 & 205 & Std. Mean Difference (Random, 95\% CI) & $0.01[-0.26,0.29]$ \\
$\quad$ 2.2 Non-arthroscopic joint & 1 & 98 & Std. Mean Difference (Random, 95\% CI) & $-0.43[-0.84,-0.02]$ \\
$\quad$ lavage & & & & \\
$\quad$ 2.3 Tidal irrigation & 2 & 237 & Std. Mean Difference (Random, 95\% CI) & $-0.04[-0.43,0.35]$ \\
\hline
\end{tabular}

Comparison 2. Any type of lavage versus sham intervention

\begin{tabular}{lccll} 
Outcome or subgroup title & $\begin{array}{c}\text { No. of } \\
\text { studies }\end{array}$ & $\begin{array}{c}\text { No. of } \\
\text { participants }\end{array}$ & Statistical method & Effect size \\
\hline 1 Pain & 7 & 567 & Std. Mean Difference (Random, 95\% CI) & $-0.11[-0.42,0.21]$ \\
1.1 Sham intervention & 4 & 392 & Std. Mean Difference (Random, 95\% CI) & $0.05[-0.21,0.32]$ \\
1.2 Placebo injection & 2 & 118 & Std. Mean Difference (Random, 95\% CI) & $-0.14[-1.19,0.91]$ \\
1.3 No control intervention & 1 & 57 & Std. Mean Difference (Random, 95\% CI) & $-0.64[-1.17,-0.11]$ \\
2 Function & 5 & 540 & Std. Mean Difference (Random, 95\% CI) & $-0.10[-0.30,0.11]$ \\
2.1 Sham intervention & 3 & 385 & Std. Mean Difference (Random, 95\% CI) & $-0.08[-0.28,0.12]$ \\
2.2 Placebo injection & 1 & 98 & Std. Mean Difference (Random, 95\% CI) & $-0.43[-0.84,-0.02]$ \\
2.3 No control intervention & 1 & 57 & Std. Mean Difference (Random, 95\% CI) & $0.23[-0.30,0.76]$ \\
\hline
\end{tabular}

Comparison 3. Joint lavage for osteoarthritis of the knee: 1 year follow up

\begin{tabular}{lcccc} 
Outcome or subgroup title & $\begin{array}{c}\text { No. of } \\
\text { studies }\end{array}$ & $\begin{array}{c}\text { No. of } \\
\text { participants }\end{array}$ & Statistical method & Effect size \\
\hline 1 Pain & 3 & 380 & Std. Mean Difference (Random, 95\% CI) & $-0.10[-0.50,0.29]$ \\
2 Function & 3 & 381 & Std. Mean Difference (Random, 95\% CI) & $-0.17[-0.38,0.03]$ \\
\hline
\end{tabular}


Analysis I.I. Comparison I Joint lavage for osteoarthritis of the knee, Outcome I Pain.

Review: Joint lavage for osteoarthritis of the knee

Comparison: I Joint lavage for osteoarthritis of the knee

Outcome: I Pain

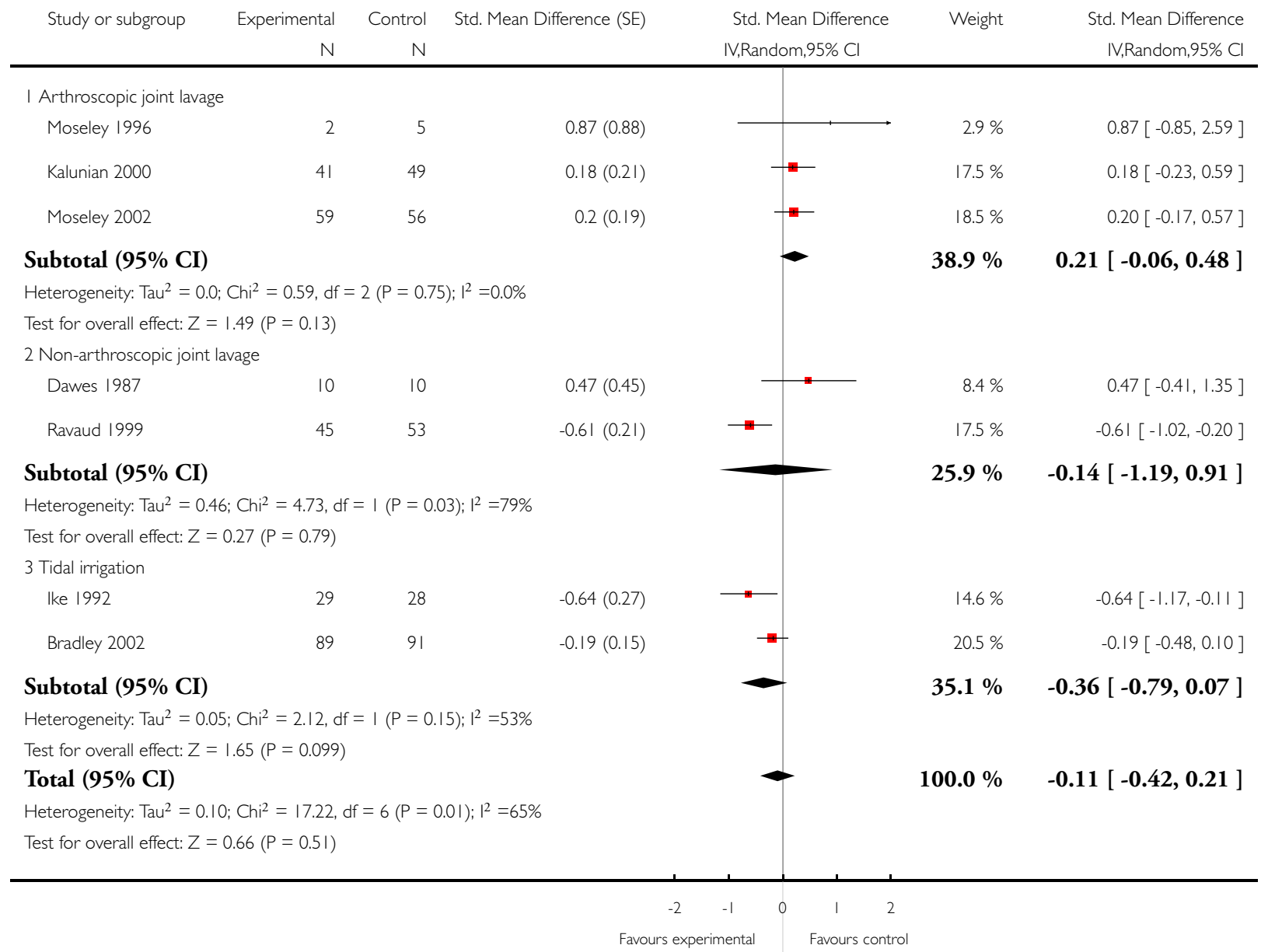




\section{Analysis I.2. Comparison I Joint lavage for osteoarthritis of the knee, Outcome 2 Function.}

Review: Joint lavage for osteoarthritis of the knee

Comparison: I Joint lavage for osteoarthritis of the knee

Outcome: 2 Function

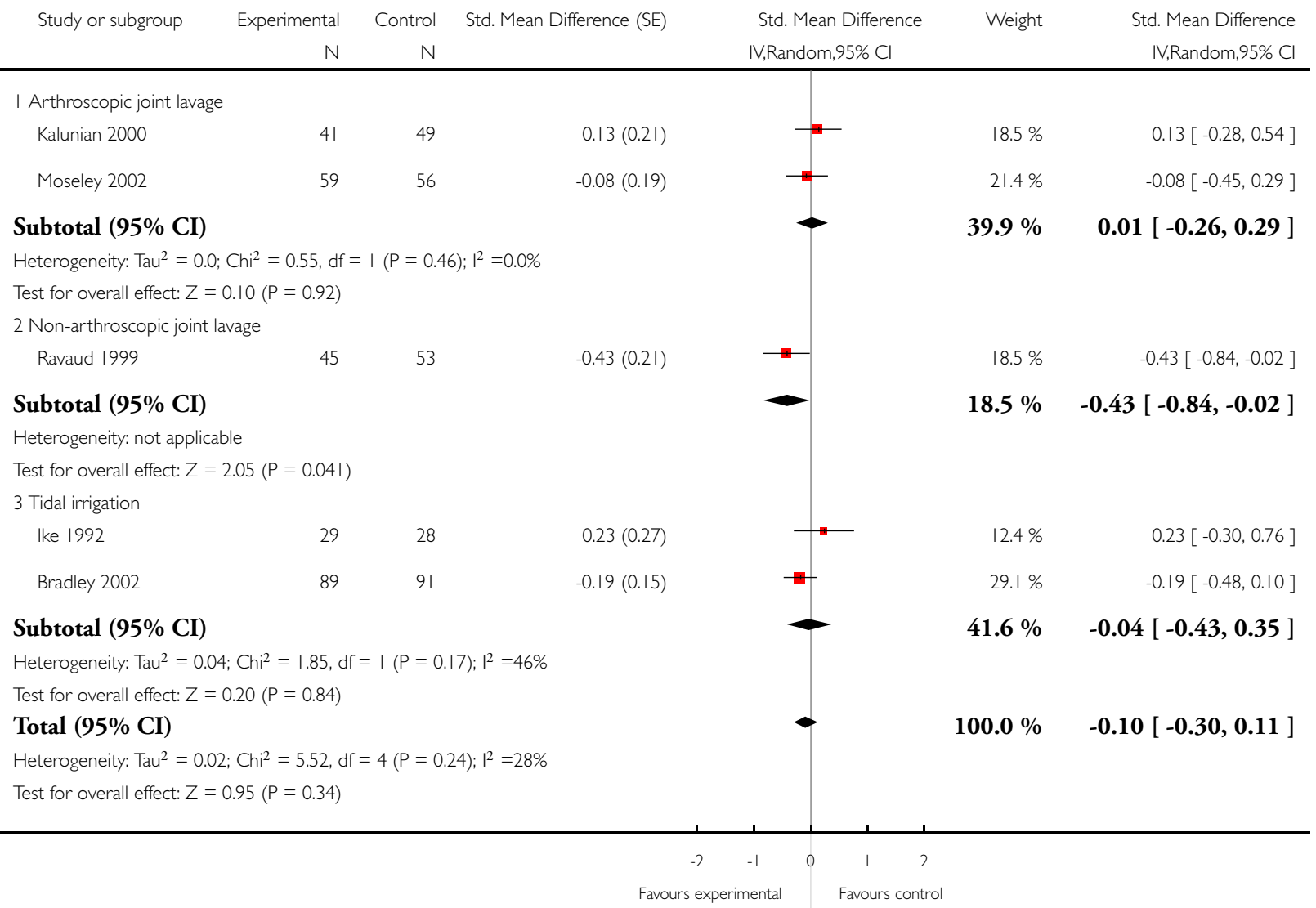


Analysis 2.I. Comparison 2 Any type of lavage versus sham intervention, Outcome I Pain.

Review: Joint lavage for osteoarthritis of the knee

Comparison: 2 Any type of lavage versus sham intervention

Outcome: I Pain

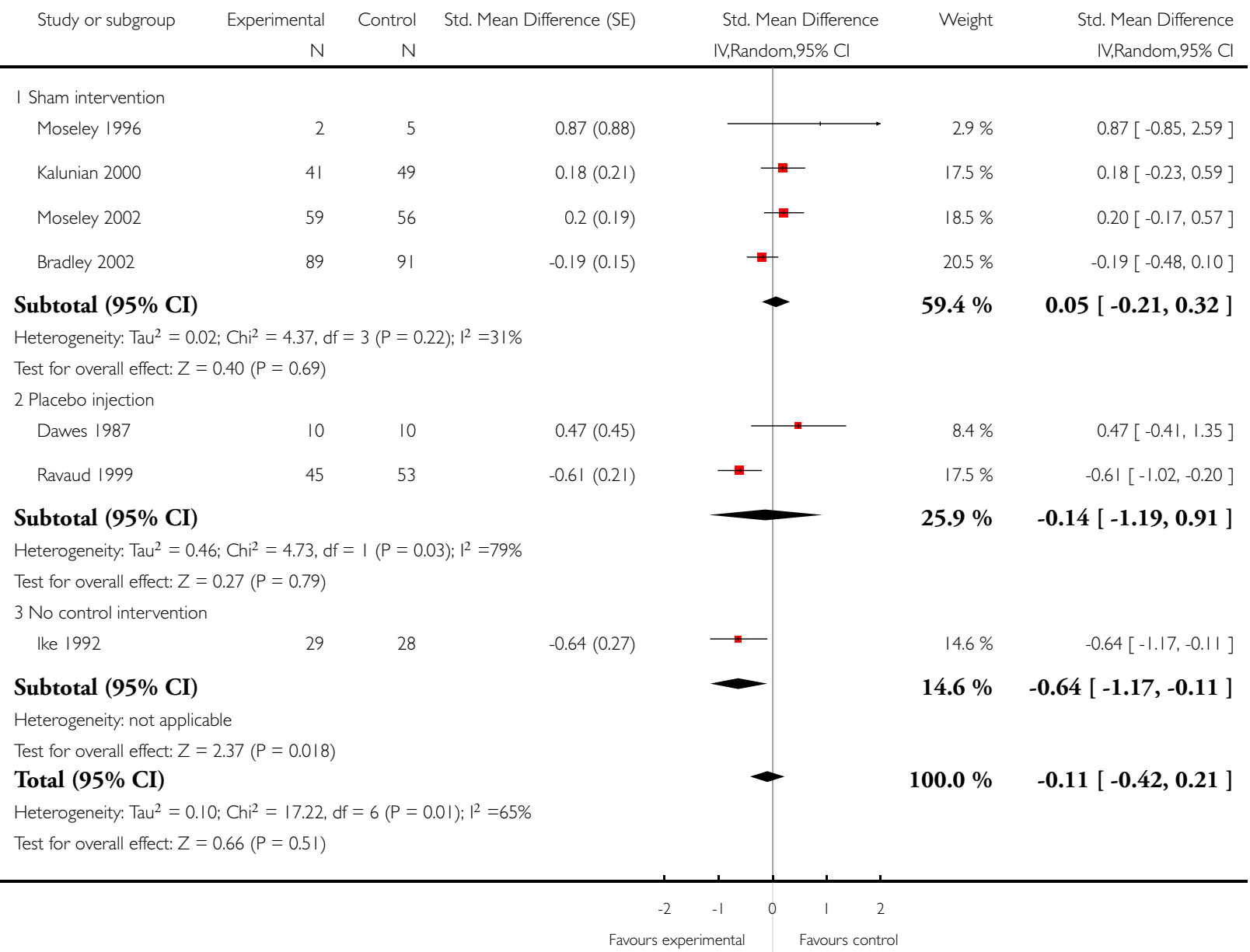




\section{Analysis 2.2. Comparison 2 Any type of lavage versus sham intervention, Outcome 2 Function.}

Review: Joint lavage for osteoarthritis of the knee

Comparison: 2 Any type of lavage versus sham intervention

Outcome: 2 Function

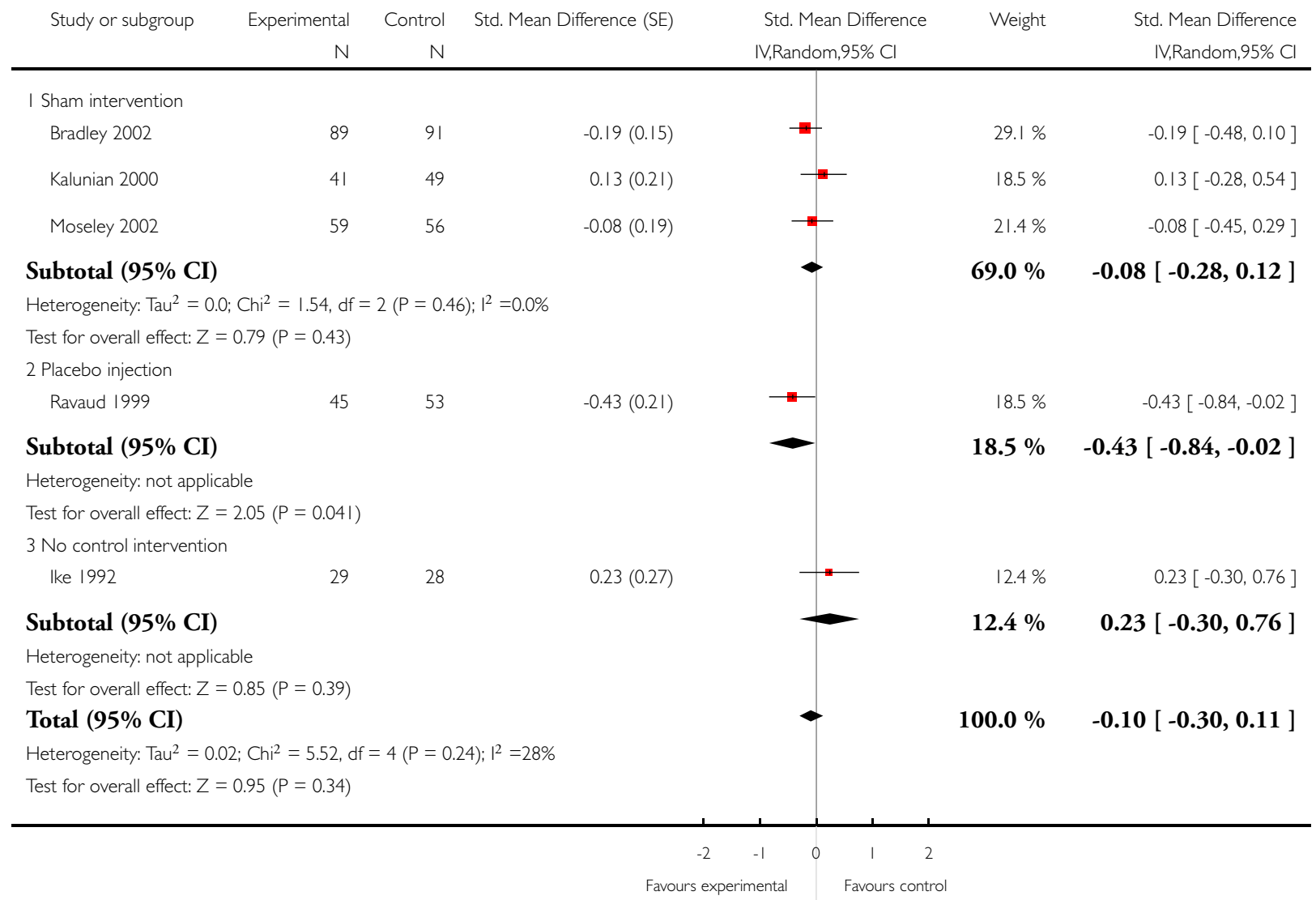


Analysis 3.I. Comparison 3 Joint lavage for osteoarthritis of the knee: I year follow up, Outcome I Pain. Review: Joint lavage for osteoarthritis of the knee

Comparison: 3 Joint lavage for osteoarthritis of the knee: I year follow up

Outcome: I Pain

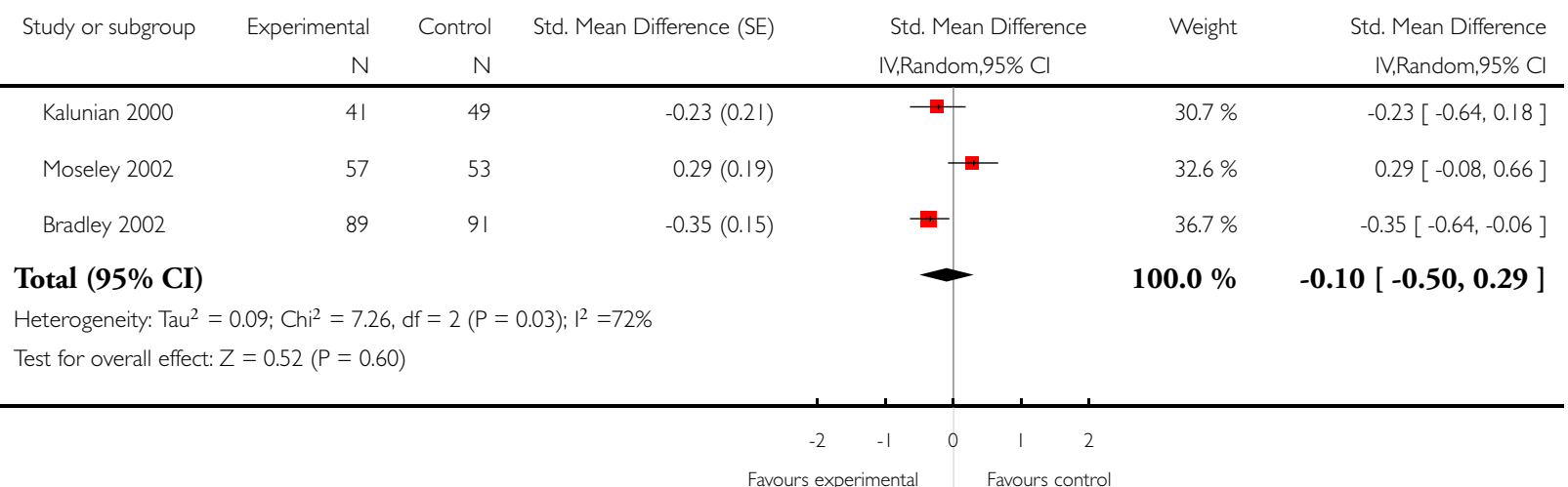

Analysis 3.2. Comparison 3 Joint lavage for osteoarthritis of the knee: I year follow up, Outcome 2 Function. Review: Joint lavage for osteoarthritis of the knee

Comparison: 3 Joint lavage for osteoarthritis of the knee: I year follow up

Outcome: 2 Function

\begin{tabular}{|c|c|c|c|c|c|c|}
\hline Study or subgroup & $\begin{array}{r}\text { Experimental } \\
\mathrm{N}\end{array}$ & $\begin{array}{r}\text { Control } \\
\mathrm{N}\end{array}$ & Std. Mean Difference (SE) & $\begin{array}{l}\text { Std. Mean Difference } \\
\text { IV,Random,95\% Cl }\end{array}$ & Weight & $\begin{array}{l}\text { Std. Mean Difference } \\
\text { IV,Random,95\% Cl }\end{array}$ \\
\hline Kalunian 2000 & 41 & 49 & $-0.18(0.21)$ & $\div-$ & $23.9 \%$ & $-0.18[-0.59,0.23]$ \\
\hline Moseley 2002 & 57 & 54 & $0(0.19)$ & 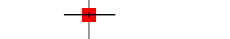 & $29.2 \%$ & $0.0[-0.37,0.37]$ \\
\hline Bradley 2002 & 89 & 91 & $-0.28(0.15)$ & + & $46.9 \%$ & $-0.28[-0.57,0.01]$ \\
\hline
\end{tabular}

Total (95\% CI)

$100.0 \% \quad-0.17[-0.38,0.03]$

Heterogeneity: $\mathrm{Tau}^{2}=0.0 ; \mathrm{Chi}^{2}=1.34, \mathrm{df}=2(\mathrm{P}=0.5 \mathrm{I}) ; \mathrm{|}^{2}=0.0 \%$

Test for overall effect: $Z=1.70(P=0.090)$

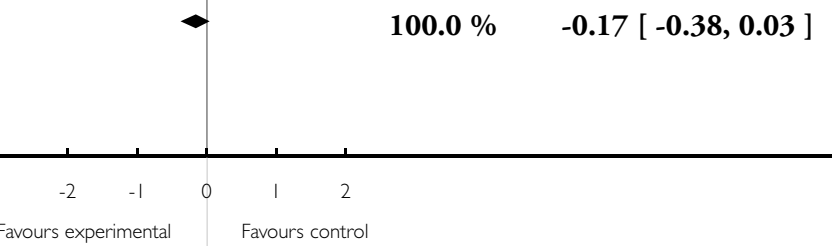


A P PENDICES

Appendix I. Search strategy

\begin{tabular}{|c|c|c|}
\hline OVID MEDLINE & OVID EMBASE & CINAHL through EBSCOhost \\
\hline $\begin{array}{l}\text { Search terms for design } \\
\text { 1. RANDOMIZED CONTROLLED } \\
\text { TRIAL.pt. } \\
\text { 2. CONTROLLED CLINICAL } \\
\text { TRIAL.pt. } \\
\text { 3. RANDOMIZED CONTROLLED } \\
\text { TRIAL.sh. } \\
\text { 4. RANDOM ALLOCATION.sh. } \\
\text { 5. DOUBLE BLIND METHOD.sh. } \\
\text { 6. SINGLE BLIND METHOD.sh. } \\
\text { 7. CLINICAL TRIAL.pt. } \\
\text { 8. exp CLINICAL TRIAL/ } \\
\text { 9. (clin\$ adj25 trial\$).ti,ab. } \\
\text { 10. ((singl\$ or doubl\$ or trebl\$ or tripl\$) } \\
\text { adj25 (blind\$ or mask\$)).ti,ab. } \\
\text { 11. PLACEBOS.sh. } \\
\text { 12. placebo\$.ti,ab. } \\
\text { 13. random\$.ti,ab. } \\
\text { 14. RESEARCH DESIGN.sh. } \\
\text { 15. COMPARATIVE STUDY.sh. } \\
\text { 16. exp EVALUATION STUDIES/ } \\
\text { 17. FOLLOW UP STUDIES.sh. } \\
\text { 18. PROSPECTIVE STUDIES.sh. } \\
\text { 19. (control\$ or prospectiv\$ or volunteer\$) } \\
\text {.ti,ab. }\end{array}$ & $\begin{array}{l}\text { Search terms for design } \\
\text { 1. RANDOMIZED CONTROLLED } \\
\text { TRIAL.sh. } \\
\text { 2. RANDOMIZATION.sh. } \\
\text { 3. Double Blind Procedure.sh. } \\
\text { 4. Single Blind Procedure.sh. } \\
\text { 5. exp CLINICAL TRIALS/ } \\
\text { 6. (clin } \$ \text { adj25 trial\$).ti,ab. } \\
\text { 7. ((singl\$ or doubl\$ or trebl\$ or tripl\$) } \\
\text { adj25 (blind } \$ \text { or mask } \$) \text { ).ti,ab. } \\
\text { 8. PLACEBO.sh. } \\
\text { 9. placebo\$.ti,ab. } \\
\text { 10. random\$.ti,ab. } \\
\text { 11. METHODOLOGY.sh. } \\
\text { 12. COMPARATIVE STUDY.sh. } \\
\text { 13. exp EVALUATION STUDIES/ } \\
\text { 14. follow up.sh. } \\
\text { 15. Prospective Study.sh. } \\
\text { 16. (control\$ or prospectiv } \$ \text { or volunteer\$) } \\
\text {.ti,ab. }\end{array}$ & $\begin{array}{l}\text { Search terms for design } \\
\text { 1. (MH "Clinical Trialst") } \\
\text { 2. (MH "Random Assignment") } \\
\text { 3. (MH "Double-Blind Studies") or (MH } \\
\text { "Single-Blind Studies") } \\
\text { 4. TX (clin\$ n25 trial\$) } \\
\text { 5. TX (sing\$ n25 blind\$) } \\
\text { 6. TX (sing\$ n25 mask\$) } \\
\text { 7. TX (doubl\$ n25 blind\$) } \\
\text { 8. TX (doubl\$ n25 mask\$) } \\
\text { 9. TX (trebl\$ n25 blind\$) } \\
\text { 10. TX (trebl\$ n25 mask\$) } \\
\text { 11. TX (tripl\$ n25 blind\$) } \\
\text { 12. TX (tripl\$ n25 mask\$) } \\
\text { 13. (MH "Placebos") } \\
\text { 14. TX placebo\$ } \\
\text { 15. TX random\$ } \\
\text { 16. (MH "Study Design+") } \\
\text { 17. (MH "Comparative Studies") } \\
\text { 18. (MH "Evaluation Research") } \\
\text { 19. (MH "Prospective Studies+") } \\
\text { 20. TX (control\$ or prospectiv\$ or volun- } \\
\text { teer\$) } \\
\text { 21. S1 or S2 or (......) or S20 }\end{array}$ \\
\hline
\end{tabular}

Search terms for Osteoarthritis

20. exp osteoarthritis/

21. osteoarthriti $\$$.ti,ab,sh.

22. osteoarthro\$.ti,ab,sh.

23. gonarthriti\$.ti,ab,sh.

24. gonarthro $\$ . t i, a b, s h$.

25. coxarthriti\$.ti,ab,sh.

26. coxarthro\$.ti,ab,sh.

27. arthros\$.ti,ab.

28. arthrot\$.ti,ab.

29. ((knee\$ or hip\$ or joint\$) adj3 (pain\$ or ach\$ or discomfort\$)).ti,ab.

30. ((knee\$ or hip\$ or joint\$) adj3 stiff\$) .ti,ab.

\section{Search terms for Osteoarthritis}

17. exp osteoarthritis/

18. osteoarthriti\$.ti,ab,sh.

19. osteoarthro\$.ti,ab,sh.

20. gonarthriti\$.ti,ab,sh.

21. gonarthro\$.ti,ab,sh.

22. coxarthriti\$.ti,ab,sh.

23. coxarthro\$.ti,ab,sh.

24. arthros\$.ti,ab.

25. arthrot\$.ti,ab.

26. ((knee\$ or hip\$ or joint\$) adj3 (pain\$ or ach $\$$ or discomfort $\$))$.ti,ab.

27. ((knee\$ or hip\$ or joint\$) adj3 stiff\$) .ti,ab.
Search terms for Osteoarthritis

22. osteoarthriti\$

23. (MH "Osteoarthritis")

24. TX osteoarthro\$

25. TX gonarthriti\$

26. TX gonarthro\$

27. TX coxarthriti\$

28. TX coxarthro\$

29. TX arthros\$

30. TX arthrot\$

31. TX knee\$ n3 pain\$

32. TX hip\$ $n 3$ pain\$

33. TX joint $\$ n 3$ pain $\$$

34. TX knee\$ $n 3$ ach\$

35. TX hip\$ $\mathrm{n} 3$ ach $\$$

36. $T X$ joint $\$ n 3$ ach $\$$

37. TX knee\$ n3 discomfort\$ 


\begin{tabular}{|c|c|}
\hline & $\begin{array}{l}\text { 38. TX hip } \$ \text { n3 discomfort } \$ \\
\text { 39. TX joint } \$ \text { n3 discomfort } \$ \\
\text { 40. TX knee } \$ \text { n3 stiff } \$ \\
\text { 41. TX hip } \$ \text { n } 3 \text { stiff } \$ \\
\text { 42. TX joint } \$ \text { n3 stiff } \$ \\
\text { 43. S22 or } S 23 \text { or (...) or } \$ 42\end{array}$ \\
\hline
\end{tabular}

\section{Search terms for joint lavage}

31. (arthroscop\$ adj40 debridement).tw.

32. (arthroscop\$ adj40 irrigation).tw.

33. (arthroscop $\$$ adj 40 lavage).tw.

34. (arthroscop\$ adj40 washout).tw.

35. exp arthroscopy/ and (exp debridement/ or exp Irrigation/)

36. (needle $\$$ adj 40 debridement).tw.

37. (needle $\$$ adj 40 irrigation).tw.

38. (needle $\$$ adj40 lavage).tw.

39. (needle $\$$ adj 40 washout).tw.

\section{Search terms for joint lavage}

28. (arthroscop\$ adj40 debridement).tw.

29. (arthroscop\$ adj40 irrigation).tw.

30. (arthroscop\$ adj40 lavage).tw.

31. (arthroscop\$ adj40 washout).tw.

32. exp arthroscopy/ and (exp debridement/ or exp Irrigation/)

33. (needle $\$$ adj 40 debridement).tw.

34. (needle $\$$ adj40 irrigation).tw.

35. (needle $\$$ adj 40 lavage).tw.

36. (needle $\$$ adj 40 washout).tw.

\section{Search terms for joint lavage}

44. TX (arthroscop\$ adj40 debridement)

45. TX (arthroscop\$ adj40 irrigation)

46. TX (arthroscop $\$$ adj 40 lavage)

47. TX (arthroscop\$ adj40 washout)

48. $\mathrm{MH}$ arthroscopy/ and ( $\mathrm{MH}$ debridement/ or MH Irrigation/)

49. TX (needle $\$$ adj 40 debridement)

50. TX (needle $\$$ adj 40 irrigation)

51. TX (needle $\$$ adj40 lavage)

52. TX (needle $\$$ adj40 washout)

53. $\mathrm{S} 44$ or $\mathrm{S} 45$ or (...) or $\mathrm{S} 52$

\section{Combining terms}

40. animal/

41. animal/ and human/

42. 40 not 41

43. or/1-19

44. or $/ 20-30$

45. or/31-39

46. and $/ 43-45$

47. 46 not 42

48. remove duplicates from 47

Combining terms
37. animal/
38. animal/ and human/
39. 37 not 38
40. or/1-16
41. or/ $17-27$
42. or/ $28-36$
43. and $/ 40-42$
44. 43 not 39
45. remove duplicates from 44

\section{Combining terms}

S21 and S43 and S53

\section{Appendix 2. CENTRAL search strategy}

\section{CENTRAI}

Search terms for Osteoarthritis

\#1. MeSH descriptor Osteoarthritis explode all trees

\#2. (osteoarthritis* OR osteoarthro* OR gonarthriti* OR gonarthro* OR coxarthriti* OR coxarthro* OR arthros* OR arthrot* OR ((knee* OR hip* OR joint*) near/3 (pain* OR ach* OR discomfort*)) OR ((knee* OR hip* OR joint*) near/3 stiff*)) in Clinical Trials

Search terms for Joint Lavage

\#3. MeSH descriptor Debridement

\#4. MeSH descriptor Irrigation

\#5. MeSH descriptor Arthroscopy

\#6. (arthroscop* near/40 debridement) OR (arthroscop* near/40 irrigation) OR (arthroscop* near/40 lavage) OR (arthroscop* near/ 40 washout) OR (needle* near/40 debridement) OR (needle* near/40 irrigation) OR (needle* near/40 lavage) OR (needle* near $/ 40$ 
\#7. (\#1 OR \#2)

\#8. (\#3 OR \#4)

\#9. (\#5 and \#8)

\#10. (\#9 or \#6)

\#11. (\#7 AND \#10) in Clinical Trials

\section{WHAT'S NEW}

Last assessed as up-to-date: 2 August 2009.

1 May 2008 Amended CMSG ID C177-R

\section{H I S T O R Y}

Protocol first published: Issue 3, 2008

Review first published: Issue 5, 2010

\section{CONTRIBUTIONS OFAUTHORS}

Study conception: Reichenbach, Rutjes, Jüni

Protocol development: Reichenbach, Rutjes, Nüesch, Trelle, Jüni

Acquisition of data: Reichenbach, Rutjes, Nüesch, Trelle, Jüni

Analysis and interpretation of data: Reichenbach, Rutjes, Nüesch, Trelle, Jüni

Drafting of the manuscript: Reichenbach, Rutjes, Jüni

Critical revision of the manuscript for important intellectual content: Reichenbach, Rutjes, Nüesch, Trelle, Jüni Statistical analysis: Nüesch, Reichenbach, Jüni

Obtained funding: Reichenbach, Jüni

Dr Reichenbach and Dr Rutjes contributed equally to this article. 


\section{DECLARATIONS OF INTEREST}

None known.

\section{SOURCES OF SUPPORT}

\section{Internal sources}

- No sources of support supplied

\section{External sources}

- Swiss National Science Foundation, Switzerland.

Financial support to update existing reviews or create new reviews in collaboration with the editorial team of the CMSG (NRP53: 4053-40-104762).

\section{DIFFERENCESBETWEEN PROTOCOLANDREVIEW}

We broadened our inclusion criteria by including also non-arthroscopic lavage trials. We used risk of bias tables to present the methodological quality of included trials and a summary of findings table to present results. 